\title{
Weakened Potential Vorticity Barrier Linked to Recent Winter Arctic Sea Ice Loss and Midlatitude Cold Extremes ${ }^{\mathfrak{O}}$
}

\author{
Dehai LuO AND XiaOdan Chen \\ Key Laboratory of Regional Climate-Environment for Temperate East Asia, Institute of Atmospheric Physics, \\ Chinese Academy of Sciences, and University of Chinese Academy of Sciences, Beijing, China \\ JAMES OVERLAND \\ NOAA/Pacific Marine Environmental Laboratory, Seattle, Washington \\ IAN SIMMONDS \\ School of Earth Sciences, The University of Melbourne, Victoria, Australia \\ YUTIAN WU \\ Lamont-Doherty Earth Observatory, Columbia University, Palisades, New York \\ PENGFEI ZHANG \\ Department of Atmospheric and Oceanic Sciences, University of California, Los Angeles, Los Angeles, California
}

(Manuscript received 13 July 2018, in final form 3 April 2019)

\begin{abstract}
A winter Eurasian cooling trend and a large decline of winter sea ice concentration (SIC) in the BarentsKara Seas (BKS) are striking features of recent climate changes. The question arises as to what extent these phenomena are related. A mechanism is presented that establishes a link between recent winter SIC decline and midlatitude cold extremes. Such potential weather linkages are mediated by whether there is a weak north-south gradient of background tropospheric potential vorticity (PV). A strong background PV gradient, which usually occurs in North Atlantic and Pacific Ocean midlatitudes, acts as a barrier that inhibits atmospheric blocking and southward cold air intrusion. Conversely, atmospheric blocking is more persistent in weakened PV gradient regions over Eurasia, Greenland, and northwestern North America because of weakened energy dispersion and intensified nonlinearity. The small climatological PV gradients over mid- to high-latitude Eurasia have become weaker in recent decades as BKS air temperatures show positive trends due to SIC loss, and this has led to more persistent high-latitude Ural-region blocking. These factors contribute to increased cold winter trend in East Asia. It is found, however, that in years when the winter PV gradient is small the East Asian cold extremes can even occur in the absence of large negative SIC anomalies. Thus, the magnitude of background PV gradient is an important controller of Arctic-midlatitude weather linkages, but it plays no role if Ural blocking is not present. Thus, the "PV barrier" concept presents a critical insight into the mechanism producing cold Eurasian extremes and is hypothesized to set up such Arcticmidlatitude linkages in other locations.
\end{abstract}

Supplemental information related to this paper is available at the Journals Online website: https://doi.org/10.1175/JCLI-D-180449.1.s1.

Corresponding author: Dr. Dehai Luo, 1dh@mail.iap.ac.cn

\section{Introduction}

Over the last two decades, rapid Arctic warming has been observed together with a large loss of sea ice concentration (SIC) during boreal winter [December-February (DJF)] (Screen and Simmonds 2010; Simmonds 2015). 
Accompanying this rapid Artic warming and sea ice loss (Comiso 2006; Gillett et al. 2008; Steele et al. 2008; Stroeve et al. 2011) have been frequent winter cold events over Eurasia and North America (Petoukhov and Semenov 2010; Outten and Esau 2012; Cohen et al. 2014; Mori et al. 2014; Kug et al. 2015; Luo et al. 2016a,b; Yao et al. 2017; Yang et al. 2018; Overland and Wang 2018). However, physical linkage mechanisms between the Arctic warming associated with SIC decline and midlatitude weather have not been unambiguously identified (Overland et al. 2015, 2016; Luo et al. 2018a; Cohen et al. 2018; Meleshko et al. 2018; L. Chen et al. 2018; Ye et al. 2018; R. Zhang et al. 2018; Simmonds 2018; Sung et al. 2018; Gu et al. 2018).

Numerous studies have suggested that the recent cold extremes are directly related to rapid Arctic warming, although whether one can attribute most of the cold extremes to intense Arctic warming or natural variability has prompted considerable discussion (Vihma 2014; Overland et al. 2015, 2016; Luo et al. 2016a,b; Shepherd 2016; McCusker et al. 2016; Yao et al. 2017). Modeling studies designed to assess the impact of sea ice reduction on midlatitude atmospheric circulation and weather patterns have produced conflicting results. Some suggest that the winter Eurasian cooling may not be directly related to the Arctic warming and SIC loss in the Barents-Kara Seas (BKS), but rather, in part, to changes in internally generated large-scale atmospheric circulation patterns themselves (Sato et al. 2014; Simmonds and Govekar 2014; McCusker et al. 2016; Sun et al. 2016) and Ural blocking (Luo et al. 2016a,b). Sato et al. (2014) emphasized the one-way effect of early winter atmospheric wave train excited by sea surface temperature (SST) anomalies over the Gulf Stream region ( $\mathrm{Li}$ 2004) on cold winter conditions over Eurasia. However, Luo et al. (2016a,b) emphasized the two-way relationship between winter atmospheric teleconnection wave trains including the roles of Ural blocking (blocking high or anticyclonic anomaly over the Ural region) and Arctic warming/sea ice decline in the BKS. They found that while Ural blocking is an internal lowfrequency mode with a 10-20-day time scale that arises mainly from the wave train propagation from the North Atlantic Ocean in the absence of stratospheric processes, it may be also affected by background Arctic warming in BKS. This Ural blocking becomes more persistent and quasi-stationary in higher latitudes, and thus leads to more intense Eurasian cooling (or more severe midlatitude Eurasian cold extremes), while enhanced BKS warming is linked to weakened westerlies over Eurasian midlatitudes (Luo et al. 2016a) and intensified North Atlantic westerlies (Yao et al. 2017). In this case, the midlatitude cold extremes are naturally influenced by background Arctic warming or sea ice loss. This result is different from the viewpoint of McCusker et al. (2016) and Sun et al. (2016) that recent Eurasian cold winters are unrelated to BKS SIC decline or warming. Thus, any connection between Arctic warming and continental cold extremes likely depends on the regional wind regime and how that may be changing as a response to Arctic sea ice decline and warming. Overall, however, a comprehensive explanation as to whether and how the Arctic warming affects midlatitude atmospheric circulation and cold extremes is still lacking (Cohen et al. 2014; Overland et al. 2015, 2016; Meleshko et al. 2018).

Warming (cooling) corresponds to reduced (enhanced) potential vorticity (PV) within the warm (cold) temperature region in the troposphere (Hoskins et al. 1985, p. 909), and thus Arctic warming can modify the subarctic-to-midlatitude meridional PV gradient. Hence PV dynamics offers the potential to explain how midlatitude atmospheric circulation and associated weather patterns are linked to the Arctic SIC loss and air temperature increases. Based on a theoretical model, Luo et al. (2018a) recently examined the roles of the PV gradient and zonal wind reductions in influencing the change in Ural blocking (UB) and found that a reduced $\mathrm{PV}$ gradient is more influential for lengthening of the UB duration than is the weakened zonal wind, while other studies emphasized the role of the mean zonal wind reduction in the lengthening of the blocking duration (Yao et al. 2017). However, how and to what extent the midlatitude cold extremes depend on the BKS SIC decline or warming were not clarified in previous studies. Building on the work of Luo et al. (2018a), we address the following two questions: 1) Under what conditions is the PV gradient a barrier or a bridge between midlatitude cold extremes and Arctic SIC decline or warming? 2) Can the Arctic SIC decline significantly affect midlatitude cold extremes? Answering these questions can deepen the understanding of the physics that dominates Arctic-midlatitude weather linkages. We propose a new viewpoint that the weakened PV barrier (i.e., reduced PV gradient) in Eurasian mid- to high latitudes, linked to recent BKS SIC decline, plays a crucial role in the increased frequency of cold extremes in East Asia and may have a role in other Arctic regions. The magnitude of background PV gradient is assessed as a key controller of Arctic-midlatitude weather linkages.

This paper is organized as follows: In section 2, we describe the data, method, PV barrier concept, and experimental design of the numerical model. The observational results are presented in section 3 . The causeand-effect relationship between the PV gradient and Ural blocking changes is discussed in section 4 . We 
present the results of the numerical experiments in section 5 , and the main findings are summarized in section 6 .

\section{Data, method, theory, and model experiment design}

\section{a. Data and the identification of blocking events}

We used daily ERA-Interim reanalysis data (http:// apps.ecmwf.int/datasets/data/interim-full-daily/levtype $=$ $\mathrm{sfc} /$ ) with a horizontal resolution of $1^{\circ} \times 1^{\circ}$ for the $500-\mathrm{hPa}$ geopotential height (Z500) and zonal wind (U500), surface air temperature (SAT), and SIC (Dee et al. 2011). We are concerned here with the cooling trend in East Asia during 1990-2013 (Cohen et al. 2014) and hence use the ERA-Interim data for the 1979-2013 period. We take the daily data of PV, as defined by the Ertel's PV (Hoskins et al. 1985), on the 315-K isentropic surface (between 300 and $200 \mathrm{hPa}$ in the latitudes north of $40^{\circ} \mathrm{N}$ ) at a horizontal resolution of $2.5^{\circ} \times 2.5^{\circ}$. The specific level chosen here is not particularly important because blocking in the mid- to high latitudes shows an equivalent barotropic structure and is relatively strong between 500 and $200 \mathrm{hPa}$ below the tropopause. The daily anomalies at each grid point are detrended and nonseasonalized by subtracting their seasonal cycle and linear trend when the detrended data are used.

The one-dimensional (1D) and two-dimensional (2D) blocking indices developed by Tibaldi and Molteni (1990, hereinafter TM) and Davini et al. (2012), respectively, are used to identify blocking events over Eurasia (Luo et al. 2016a,b) and in the Northern Hemisphere (NH). The 1D TM index is used to identify the number of blocking events in the Ural region $\left(30^{\circ}-\right.$ $90^{\circ} \mathrm{E}$ ) (Luo et al. 2016a), while the 2D index identifies blocking frequency defined as a percentage of instantaneous blocking days with respect to the total days of a winter.

In this study, Monte Carlo testing is performed to examine the statistical significances of composite field patterns and their domain-averaged time series in different states. A Student's $t$ test is also used to examine the significance of the linear trend of the time series. These methods are fully described in Wilks (2011).

\section{b. Linear energy dispersion theory}

The pioneer work of Yeh (1949) indicated that the blocking maintenance is due to weak energy dispersion in high latitudes. Because the meridional wind strength related to BKS warming prior to the blocking onset is small and not important for the UB energy dispersion or duration (Luo et al. 2018a), we can consider a slowly varying zonal flow as a background of blocking. We first describe a linear Rossby wave theory to emphasize whether the energy dispersion of linear Rossby waves is determined by the magnitude of the meridional gradient of the background tropospheric PV related to background westerly winds. For this we use the linearized PV equation (Luo 2005), superimposed on a slowly varying mean zonal flow, $U[U=-(\partial \bar{\psi} / \partial y)$, where $\bar{\psi}$ is the background streamfunction]. The nondimensional linear equation of Rossby wave for a barotropic disturbance $\psi^{\prime}$, scaled by the characteristic length $\tilde{L}(\sim 1000 \mathrm{~km})$ and wind speed $\tilde{U}\left(\sim 10 \mathrm{~m} \mathrm{~s}^{-1}\right)$, can be expressed as

$$
\left(\frac{\partial}{\partial t}+U \frac{\partial}{\partial x}\right)\left(\nabla^{2} \psi^{\prime}-F \psi^{\prime}\right)+\left(Q_{y}+F U\right) \frac{\partial \psi^{\prime}}{\partial x}=0,
$$

where $\psi^{\prime}$ is the disturbance streamfunction, $Q_{y}=\beta-$ $U_{y y}\left(U_{y y}=\partial^{2} U / \partial y^{2}\right)$ is the meridional gradient of the absolute vorticity $Q=f_{0}+\beta y-U_{y}\left(U_{y}=\partial U / \partial y\right)$ of the background flow $U$, where $f_{0}$ is a constant nondimensional Coriolis parameter, and $F=\left(\tilde{L} / R_{d}\right)^{2}$. Also here $R_{d}$ is the radius of Rossby deformation and $\beta=\tilde{L}^{2} \beta_{0} / \tilde{U}$ is the nondimensional form of the meridional gradient $\beta_{0}$ of the Coriolis parameter.

Using the Wentzel-Kramers-Brillouin method (Luo 2005), the dispersion relation of the linear Rossby wave for a solution $\exp [i(k x+m y-\omega t)]$ can be obtained as

$$
\omega=U k-\frac{\left(Q_{y}+F U\right) k}{k^{2}+m^{2}+F},
$$

where $\omega$ is the frequency and $k$ and $m$ are the zonal and meridional wavenumbers, respectively.

In the barotropic case, we have $\mathrm{PV}=\nabla^{2} \bar{\psi}-F \bar{\psi}+$ $\beta y+f_{0}$ for the background streamfunction $\bar{\psi}$ and hence $\mathrm{PV}_{y}=\partial \mathrm{PV} / \partial y=Q_{y}+F U$. The group velocity and phase speed of the Rossby waves are obtained as

$$
\begin{gathered}
C_{g}=\partial \omega / \partial k=U-\frac{\mathrm{PV}_{y}\left(m^{2}+F-k^{2}\right)}{\left(k^{2}+m^{2}+F\right)^{2}} \\
C_{p}=\frac{\omega}{k}=U-\frac{\mathrm{PV}_{y}}{k^{2}+m^{2}+F} .
\end{gathered}
$$

The energy dispersion of the linear Rossby wave can be characterized by the difference between its group velocity and phase speed, namely,

$$
C_{g p}=C_{g}-C_{p}=\frac{2 k^{2} \mathrm{PV}_{y}}{\left(k^{2}+m^{2}+F\right)^{2}} .
$$

It is found that $C_{g p}$ will be small if $\mathrm{PV}_{y}$ is small. In the limiting case of $\mathrm{PV}_{y} \rightarrow 0$, the group velocity and the phase speed approach $U$. As a result, the wave packet and carrier wave are moving with speed $U$, but with little 
energy dispersion. Hence in this case the linear Rossby wave is expected to have a weak energy dispersion and a long lifetime, but may not be quasi-stationary. Thus, our results differ from what Yao et al. (2017) found regarding the importance of $U$ in inducing UB episodes. For a given $\mathrm{PV}_{y}$ the energy dispersion from the packet will be smaller (i.e., longer-lived pattern) for the longerscale zonal waves because $C_{g p} \rightarrow 0$ as $k \rightarrow 0$. That is, the longer waves will be favored for longer lifetimes. In fact, the magnitude of $\mathrm{PV}_{y}$ depends on the values of $U$ and $U_{y y}$ because $\mathrm{PV}_{y}=\beta-U_{y y}+F U$. While Eq. (4) reveals what determines the energy dispersion of linear Rossby waves, this linear theory is more likely suitable for the beginning stage of the blocking onset when the amplitudes are small. In the next section, we will demonstrate that the magnitude of $\mathrm{PV}_{y}$ is also important for the behavior of blocking system in a nonlinear framework.

\section{c. A nonlinear theory of blocking events and definition of the $P V$ barrier}

In a more general case, we can make use of the nonlinear multiscale interaction (NMI) model of blocking events proposed and developed by Luo and his collaborators (Luo 2000, 2005; Luo and Li 2000; Luo et al. 2014, 2018a). Here, we briefly describe this NMI model and show how it allows us to introduce the PV barrier concept.

For a slowly varying zonal wind $U$, the analytical solution of the nondimensional planetary-scale barotropic streamfunction field $\psi_{P}$ of an eddy-driven blocking from the barotropic NMI model, scaled by characteristic scale $\tilde{L}(\sim 1000 \mathrm{~km})$ and velocity $\tilde{U}\left(\sim 10 \mathrm{~m} \mathrm{~s}^{-1}\right)$, in a $\beta$-plane channel with a width of $L_{y}$ can be obtained as

$$
\begin{aligned}
& \psi_{P}=-\int_{0}^{y} U\left(y^{\prime}\right) d y^{\prime}+\psi \approx-\int_{0}^{y} U\left(y^{\prime}\right) d y^{\prime}+\psi_{B}+\psi_{m}, \\
& \psi_{B}=B \sqrt{\frac{2}{L_{y}}} \exp [i(k x-\omega t)] \sin (m y)+\mathrm{cc}, \\
& \psi_{m}=-|B|^{2} \sum_{n=1}^{\infty} q_{n} g_{n} \cos (n+1 / 2) m y, \\
& i\left(\frac{\partial B}{\partial t}+C_{g} \frac{\partial B}{\partial x}\right)+\lambda \frac{\partial^{2} B}{\partial x^{2}}+\delta|B|^{2} B \\
& +G f_{0}^{2} \exp [-i(\Delta k x+\Delta \omega t)]=0,
\end{aligned}
$$

where $\omega=U k-\mathrm{PV}_{y} k /\left(k^{2}+m^{2}+F\right), C_{\mathrm{g}}=U-$ $\left[\mathrm{PV}_{y}\left(m^{2}+F-k^{2}\right) /\left(k^{2}+m^{2}+F\right)^{2}\right], g_{n}=8 /\{m[4-(n+$ $\left.\left.1 / 2)^{2}\right] L_{\mathrm{y}}\right\}, q_{n}=q_{N n} / \mathrm{PV}_{y}, \lambda=\lambda_{0} \mathrm{PV}_{y}, \lambda_{0}=\left[3\left(m^{2}+F\right)-k^{2}\right]$ $k /\left(k^{2}+m^{2}+F\right)^{3}, \delta=\delta_{N} / \mathrm{PV}_{y}, \lambda_{0}>0, \delta_{N}>0$, and
$|B|^{2}=B B^{*}$, with $B^{*}$ being the complex conjugate of $B$; $B$ denotes the complex envelope amplitude of the blocking streamfunction anomaly $\psi_{B}$ having zonal and meridional wavenumbers $k$ and $m=-2 \pi / L_{y}$, respectively. Note that in Eq. (5d) $f_{0}$ represents the amplitude distribution of the preexisting incident synoptic-scale eddies having two modes with the wavenumber $\left(\tilde{k_{j}}, m / 2\right)$ and frequency $\tilde{\omega}_{j}=U \tilde{k}_{j}-\mathrm{PV}_{y} \tilde{k}_{j} /\left(\tilde{k}_{j}^{2}+\right.$ $\left.m^{2} / 4+F\right)(j=1,2)($ Luo 2000, 2005; Luo et al. 2014), and cc denotes the complex conjugate of its preceding term. Note that $G, \Delta k=k-\left(\tilde{k}_{2}-\tilde{k}_{1}\right)$, and $\Delta \omega=\tilde{\omega}_{2}-$ $\tilde{\omega}_{1}-\omega$ in Eq. (5d) are the same as those in Luo et al. (2018b), and $q_{N n}$ and $\delta_{N}$ can be found in Luo et al. (2018a). Here, $G, \Delta k, q_{N n}$, and $\delta_{N}$ are fixed constants that are independent of $U$ or $\mathrm{PV}_{y}$.

Also, in the above $\psi_{m}$ is the streamfunction anomaly of the mean zonal wind change in the presence of the blocking anomaly $\psi_{B}$, which reflects the feedback of the blocking formation on the mean westerly wind and PV gradient prior to the blocking onset. Equation (5d) shows that the spatiotemporal evolution of the blocking amplitude can be described by a nonlinear Schrödinger equation with an eddy forcing. Thus, one can use this NMI model to examine how a blocking event with a 10 20-day time scale occurs for a given initial condition and eddy parameters. The most important aspect of the NMI model is that it emphasizes the role of preexisting synoptic-scale eddies in the blocking life cycle rather than the role of eddy straining or wave breaking. Thus, it can consider the effect of background condition changes on blocking. This model also reveals that the eddy straining or wave breaking is a result of the blocking formation rather than a cause. In the NMI model, $\lambda$ is the linear dispersion effect term and proportional to the background $\mathrm{PV}_{y}$ or $C_{g p}$ because $C_{g p} \propto \mathrm{PV}_{y}$, whose magnitude reflects whether the blocking anomaly has strong energy dispersion. We also find that $\delta=\delta_{N} / \mathrm{PV}_{y}$ is the nonlinearity strength and proportional to the inverse of $\mathrm{PV}_{y}$. Obviously, it is inferred that the blocking has weak dispersion and strong nonlinearity as $\mathrm{PV}_{y}$ is small, especially in high latitudes. Thus, the blocking can maintain its longer lifetime in the smaller background $\mathrm{PV}_{y}$ region. To some extent, the smaller background $\mathrm{PV}_{y}$ region may be considered as a nearly nondispersion $\left(C_{g p} \approx 0\right)$ media that favors the maintenance of blocking. However, it may play a suppressive role if the amplitude of UB is too large, which will be discussed in another paper.

On the other hand, the zonal extent of the blocking energy distribution reflects whether the blocking can be maintained or not. When the blocking energy is distributed in a narrower zonal region, it can have a longer persistence (Luo 2000), and this energy is represented by the magnitude and zonal distribution of $|B|$. Some 
UB events arise from the propagation of wave trains coming from the North Atlantic (Luo et al. 2016b) and the NMI model can describe the processes relevant to this (Luo et al. 2018b). Thus, we may use the solution of Eq. (5d) without eddy forcing to indicate how the zonal distribution of the blocking energy is related to the magnitude of the background $\mathrm{PV}_{y}$.

Similar to Luo (2000), the wave packet amplitude $|B|$ of blocking derived from Eq. (5d) without forcing is

$$
\begin{aligned}
|B| & =M_{0} \sec h\left[(\sqrt{\delta / 2 \lambda}) M_{0}\left(x-C_{g} t\right)\right] \\
& =M_{0} \operatorname{sech}\left[\left(\sqrt{\delta_{N} / 2 \lambda_{0}}\right)\left(M_{0} /\left|\mathrm{PV}_{y}\right|\right)\left(x-C_{g} t\right)\right]
\end{aligned}
$$

(where $M_{0}$ denotes the maximum amplitude at $x=0$ and $t=0$ ) (Luo et al. 2018b). Note that $M_{0}$ becomes timedependent once the blocking is amplified by preexisting synoptic-scale eddies (Luo 2000). Although $C_{g}$ represents the zonal propagation speed of the blocking energy or wave packet, whether the blocking energy is concentrated in a narrow zonal region is mainly determined by its difference with the phase speed (the value of $C_{g p}$ ) or the magnitude of $\mathrm{PV}_{y}$ if the blocking amplitude $M_{0}$ is fixed. When $\mathrm{PV}_{y}$ is small, $M_{0} /\left|\mathrm{PV}_{y}\right|$ is large. The energy of the blocking wave packet is more easily concentrated in a smaller zonal region in this case, even though the blocking amplitude $M_{0}$ varies with time during the blocking life cycle, and thus, it is likely that blocking with a longer lifetime would be found in the smaller $\mathrm{PV}_{y}$ region. The suggestion thus presents itself that small $\mathrm{PV}_{y}$ represents a favorable environment for longer blocking duration. The numerical solution of Eq. (5) for given eddy parameters and initial amplitudes also indicates this point (not shown). It should be pointed out that the small zonal scale of $|B|$ does not correspond to the blocking anomaly having small zonal scales because the zonal scale of the blocking anomaly $\psi_{B}$ depends not only on the zonal scale of the blocking wave packet $|B|$, but also on the zonal scales of the blocking carrier wave and initial blocking anomaly. Thus, we are unable to use the zonal scale of the blocking wave packet to represent the zonal scale of the observed blocking anomaly (Luo 2000). The nonlinear phase speed $C_{\mathrm{NP}}$ of blocking in the form of

$$
\begin{aligned}
C_{\mathrm{NP}} & =\omega / k-\delta M_{0}^{2} /(2 k) \\
& =U-\mathrm{PV}_{y} /\left(k^{2}+m^{2}+F\right)-\delta_{N} M_{0}^{2} /\left(2 k \mathrm{PV}_{y}\right)
\end{aligned}
$$

can be obtained as in Luo (2000) when the eddy forcing is not too strong. This formula may be used to explain how the Arctic warming influences the movement of blocking through changing the background westerly wind $U$ and associated $\mathrm{PV}_{y}$. When the NMI model is applied to a specific region, the domain-averaged value of the height anomaly over the blocking region is chosen as the value of $M_{0}$.

Because the long-lived blocking corresponds to a persistent westerly jet meander (Luo 2000) and a persistent southward intrusion of cold air on its downstream side, such cold air can easily cross the small $\mathrm{PV}_{y}$ region. Put another way, the small PV gradient region is much less likely to obstruct the southward intrusion of cold Arctic air. Based on the theoretical discussion above, the region with a small meridional gradient of the background PV can be referred to as a weak PV barrier region.

\section{d. Model experiment design}

To further illustrate the causal relationships between the BKS SIC loss/warming, PV gradient reduction, and blocking persistency increase, we have performed both comprehensive and dry dynamical core numerical model experiments. The comprehensive model experiments analyzed here are the same as in P. Zhang et al. (2018a), who employed the Specified Chemistry Whole Atmosphere Community Climate Model, version 4.0 (SC-WACCM4), which is a stratosphere-resolving atmospheric general circulation model that is a component of the National Center for Atmospheric Research (NCAR) Community Earth System Model version 1.2 (Hurrell et al. 2013; Marsh et al. 2013). SC-WACCM4 has specified, rather than full interactive, chemistry as in WACCM4. The removal of interactive chemistry has little impact on the climatology and variability of the atmospheric circulation below $55 \mathrm{~km}$ and greatly decreases the computational cost (Smith et al. 2014). The SC-WACCM4 is integrated with a horizontal resolution of $1.9^{\circ}$ latitude $\times 2.5^{\circ}$ longitude and 66 vertical levels with a model lid at about $140 \mathrm{~km}$. The control experiment (CTRL run) uses a repeating seasonal cycle of SIC and SST, averaged over the period from 1980 to 1999 from CMIP5 CESM-WACCM4 historical runs. The perturbation experiment (BKS run) is similar but the SIC over the BKS region is replaced by the future projected SIC averaged from 2080 to 2099, which is taken from CMIP5 CESM-WACCM representative concentration pathway 8.5 (RCP8.5) runs. The SST in the BKS run is also replaced with RCP-8.5 SST in the open water areas that used to be covered by sea ice in the CTRL run. Although the BKS run is prescribed with RCP8.5 SIC, the amount of SIC decline in the BKS run is actually comparable to that in observations in recent decades [see the discussion of sea ice forcing in the supplementary information of P. Zhang et al. (2018a)]. Both the CTRL and BKS experiments are integrated for $60 \mathrm{yr}$, and the last $50 \mathrm{yr}$ are extracted for analysis. Details of experiment design can be found in $\mathrm{P}$. Zhang et al. 
(2018a), but note that our BKS run was referred to as BKS_FL there. Since there is no isentropic PV output in these experiments, we simply calculate the meridional gradient of the 500-hPa PV in the form of $\mathrm{PV}_{y}=\beta-$ $U_{y y}+F U(F \approx 1)$ as an approximation of $\mathrm{PV}_{y}$. Such a treatment is acceptable because the blocking has an equivalent barotropic structure.

In addition, to explore the robustness of the model results and to demonstrate whether the complex physical processes including moist feedbacks are influential in UB development, the numerical experiments about these problems are performed using the newest version of Geophysical Fluid Dynamics Laboratory (GFDL) spectral dry dynamical core model described by $\mathrm{Wu}$ and Reichler (2018). A brief description of the idealized GFDL dry model and its experiment design are presented in the online supplemental material. For the CTRL and BKS experiments, the GFDL dry model is integrated for 20000 days $(\sim 55 \mathrm{yr})$ and the analyses are based on 50 winter years, with the first 1000 days of spinup discarded here.

\section{Roles of SIC decline and meridional PV gradients in the Eurasian cold extremes}

In this section, we examine the roles of BKS SIC decline and associated PV gradient in winter Eurasian cold extremes. The effect of the SIC decline on the cold extremes may be by means of the PV gradient and UB changes. To some extent, the UB is an important bridge of their linkages because the quasi-stationary blocking (Berggren et al. 1949; Rex 1950) plays a key role in midlatitude cold extremes (Yang et al. 2018) via the radiative cooling (Yao et al. 2017) and cold temperature advection processes (Iwasaki et al. 2014; Shoji et al. 2014) and it is significantly influenced by the background PV gradient as noted below.

\section{a. Regions of Northern Hemisphere blocking and their link with meridional $P V$ gradient}

In this subsection, we first explore whether the region of climatological blocking frequency in winter is related to the spatial distribution of the winter PV gradient in observations before examining the roles of the SIC decline and meridional PV gradients in the Eurasian cold extremes. We use the daily PV data on the 315-K isentropic surface to calculate the meridional gradient of DJF-mean PV as the winter PV gradient. Figure 1a shows that the winter PV gradient has maxima regions over the North Atlantic Ocean (from $90^{\circ}$ to $30^{\circ} \mathrm{W}$ ) and North Pacific Ocean (from $100^{\circ}$ to $180^{\circ} \mathrm{W}$ ) midlatitudes where strong North Atlantic and Pacific jets prevail (Fig. 1c).
Here, we can use the strength of the DJF-mean PV gradient or the change of the PV barrier as an indicator of blocking frequency or duration and the severity of associated cold extremes because the change in the blocking duration is linked to the magnitude of $\mathrm{PV}_{y}$ (Luo et al. 2018a) and long-lived blocking leads to intense cold extremes or cold anomalies in winter (Luo et al. 2016a; Yao et al. 2017). It is found that there are small PV gradients in two main regions: the domain extending from Europe to the Ural region and that from the northeastern Pacific to the western part of North America. There is a further weak PV gradient region over Greenland. The small PV gradient is also seen in high latitudes of the western North Pacific. It is further noted that the blocking frequency in the region from North Atlantic to Eurasia has three main peak (or center) regions, namely Greenland, the European continent, and the Ural Mountains. This blocking frequency distribution was first found by Diao et al. (2006) [see also Davini et al. (2012) and Cheung et al. (2013)], and is also modulated by the phase of NAO and the strength of North Atlantic westerly winds (Luo et al. 2015a,b). The continental blocking tends to occur in the downstream side of European continent near the Ural Mountains when the North Atlantic westerly wind is stronger (Luo et al. 2015a). We further see that weak PV barrier (or small PV gradient) regions (Fig. 1a) correspond to regions of high blocking frequency (as defined by the percentage of blocking days with respect to the total number of winter days) (Fig. 1b), and this frequency is smaller in the strong PV barrier region. Thus, it can be inferred, based on the earlier considerations, that in a climatological sense a high blocking frequency only appears in the weak PV barrier region. The location of blocking events is dominated by the collocation of the weak magnitude of the PV gradient. The spatial distribution of blocking frequency better matches the shape of the weak PV barrier region (Figs. 1a,b). Below, we examine the linkages among Eurasian cold extremes, UB, SIC decline, and PV gradient from linear trend and interannual time scales using a daily evolution perspective.

\section{b. Trends in PV gradient, blocking frequency, cold extremes, atmospheric circulation pattern, SIC and zonal winds, and their linkages}

Observations reveal that the pronounced Arctic warming or SIC trend observed since the 1980s is related to the Arctic ocean surface warming trend (Steele et al. 2008), human influence (Gillett et al. 2008), and atmospheric circulation changes (Stroeve et al. 2011; Luo et al. 2016a, 2017; Woods and Caballero 2016; Kelleher and Screen 2018; Screen et al. 2018). Thus, it is useful to examine whether the linear trends of the atmospheric 

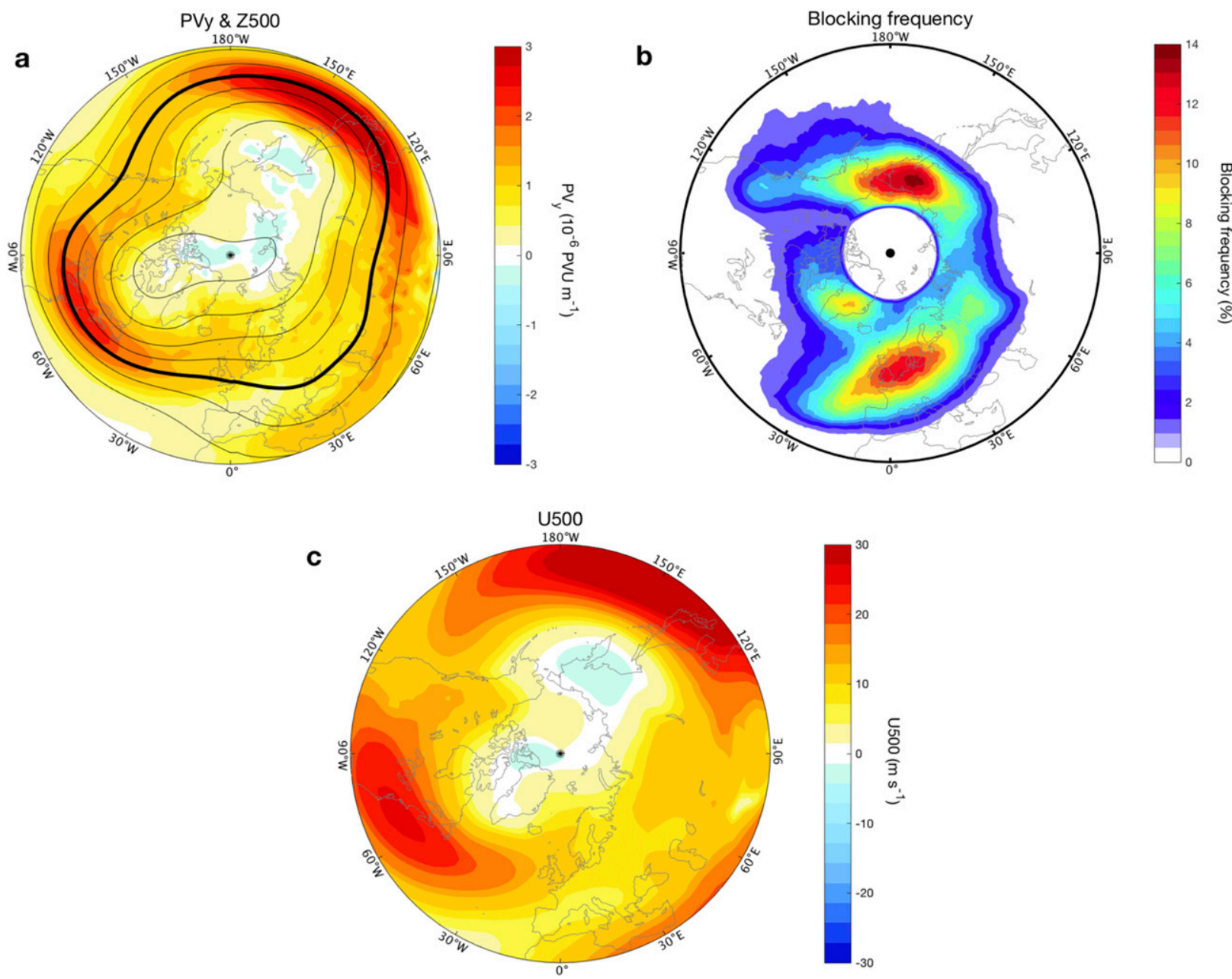

FIG. 1. (a) DJF-mean Z500 [contour interval $(\mathrm{CI})=100 \mathrm{gpm}$ ] and meridional potential vorticity gradient $\mathrm{PV}_{y}$ (color shading; $10^{-6}$ PVU m${ }^{-1}$, where $1 \mathrm{PVU}=10^{-6} \mathrm{~m}^{2} \mathrm{~s}^{-1} \mathrm{~K} \mathrm{~kg}^{-1}$ ) on the $315-\mathrm{K}$ isentropic surface; the thick black contour line represents 5500 gpm. (b) Horizontal distribution of DJF-mean blocking frequency (\%; color shading), as represented by the percentage of instantaneous blocking days with respect to the total days of a winter based on the two-dimensional TM index. (c) DJF-mean 500-hPa zonal winds (U500) during 1979-2013 winters.

circulation pattern and cold extremes are related to the SIC decline trend through the trend of the PV gradient. We calculate linear trends of PV gradient, blocking frequency, cold extremes, SIC, Z500, U500, and SAT during 1979-2013. The DJF-mean meridional PV gradient shows a declining trend in a wide region of Eurasia south of the BKS and in a relatively small region south of Greenland (Fig. 2a). At the same time, the blocking frequency shows increasing trends in the Ural region, in the BKS, and over Greenland and the mid- to highlatitude North Atlantic (Fig. 2b). We also note that the reduction of Atlantic $\mathrm{PV}_{y}$ is not statistically significant, and hence a physical argument cannot be based on that. Thus, these results suggest that the increased trend of the UB frequency over Eurasia (red shading region in Fig. 2b) might be related to the decreased trend of the meridional PV gradient (blue shading region in Fig. 2a). Increases in the high-latitude blocking frequency are particularly evident in the Ural high latitudes and its east side probably due to BKS warming, which are located over the north side of a weak PV gradient region (blue shading region of Fig. 2a).

The SIC shows a large decline in BKS and a small decline in the Baffin Bay, Davis Strait, and Labrador Sea (BDL) (blue-shaded region in Fig. 2d). The Z500 anomaly exhibits a negative Arctic Oscillation $\left(\mathrm{AO}^{-}\right)$ pattern concomitant with the SIC decline (contour line in Fig. 2c). Such a pattern is mainly related to the Arctic warming due to sea ice loss in the region from BKS to Labrador Sea (Luo et al. 2016a). Because the sea ice decline is stronger in the $\mathrm{BKS}$ than in the $\mathrm{BDL}$, the $\mathrm{AO}^{-}$ exhibits an asymmetric pattern with a large positive 

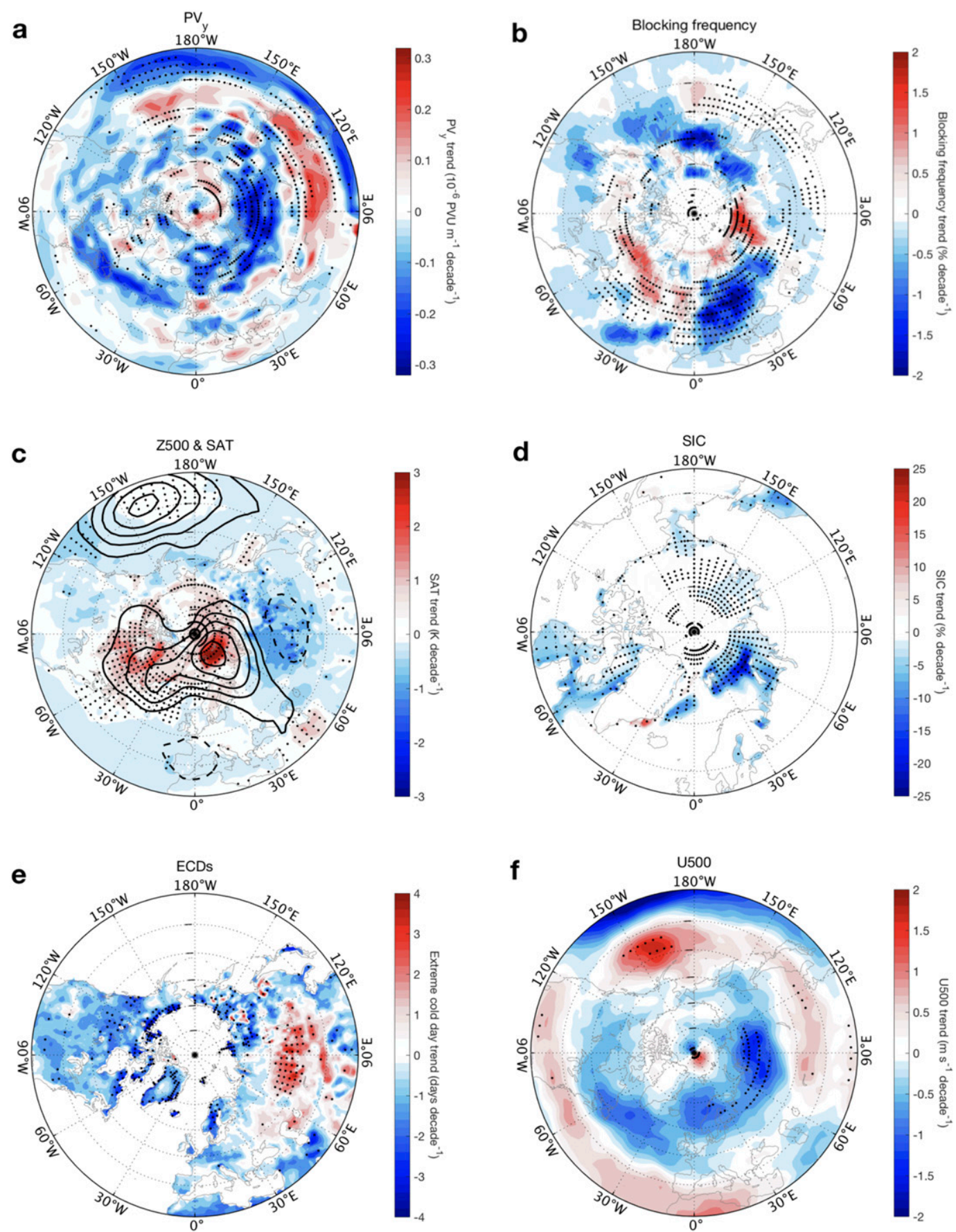

FIG. 2. Linear trends of DJF-mean (a) meridional PV gradient anomaly on the $315-\mathrm{K}$ isentropic surface, (b) blocking frequency (\%), (c) Z500 (CI $=5 \mathrm{gpm})$ and SAT (color shading) anomalies, (d) SIC anomaly in BKS (30 $\left.90^{\circ} \mathrm{E}, 65^{\circ}-85^{\circ} \mathrm{N}\right)$, (e) extreme cold days (ECDs) over East Asia $\left(60^{\circ}-120^{\circ} \mathrm{E}, 40^{\circ}-60^{\circ} \mathrm{N}\right)$, and (f) 500 -hPa zonal wind anomaly during 1979-2013. The stippling indicates regions over which the trend is statistically significant $(p<0.05$; Student's $t$ test). The ECDs are defined as the 5\% of all winter cold days that are most extreme during 1979-2013.

height anomaly extending toward midlatitudes along the upstream side of the Ural Mountains and has been referred to as a negative Arctic response oscillation $\left(\mathrm{ARO}^{-}\right)$(Luo et al. 2016a). For this $\mathrm{AO}^{-}$pattern, a cold temperature anomaly is seen over midlatitude Eurasia or Siberia (Fig. 2c) and located mainly in the occurrence region of extreme cold days (ECDs; these are defined to be the coldest $5 \%$ of all winter days during the 1979-2013 period) (Fig. 2e). 

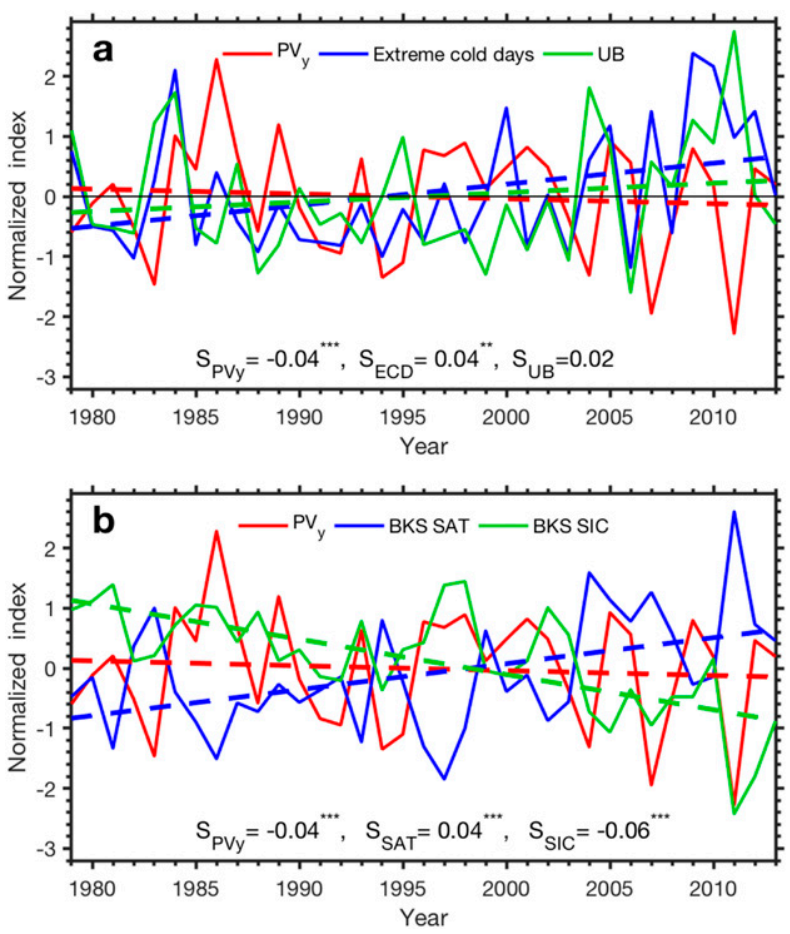

FIG. 3. Time series of normalized DJF-mean domain-averaged $\mathrm{PV}$ gradient anomaly over the region $30^{\circ}-90^{\circ} \mathrm{E}, 50^{\circ}-70^{\circ} \mathrm{N}$ [in both (a) and (b)]; (a) UB frequency (blocking days) over the region $60^{\circ}-$ $75^{\circ} \mathrm{N}, 30^{\circ}-90^{\circ} \mathrm{E}$; and ECDs over the region $60^{\circ}-120^{\circ} \mathrm{E}, 40^{\circ}-60^{\circ} \mathrm{N}$ and (b) SAT and SIC anomalies over the BKS $\left(30^{\circ}-90^{\circ} \mathrm{E}, 65^{\circ}-\right.$ $85^{\circ} \mathrm{N}$ ) during $1979-2013$. The $95 \%$ (99\%) confidence level of the slope of the straight line for the Student's $t$ test is indicated by two (three) asterisks.

Although the increased UB frequency is located on the downstream side of the $\mathrm{AO}^{-}$(Fig. 2b), it probably constitutes a part of the $\mathrm{AO}^{-}$pattern and is influenced by the $\mathrm{AO}^{-}$as a background circulation. Thus, it is likely that a portion of the trend of ECDs is not only linked to the $\mathrm{AO}^{-}$pattern trend, but also the trend of $\mathrm{UB}$ (Fig. 2b). Moreover, because the trend of the winter U500 (Fig. 2f) shows a pattern similar to that of the PV gradient (Fig. 2a), the latter trend is mainly related to the trend change of zonal winds in strength and spatial structure related to BKS warming through reduced meridional temperature gradient. It is also found that the BKS warming and $\mathrm{AO}^{-}$pattern trends are more intense during 1990-2013 than their 1979-2013 trends in that the BKS sea ice declining trend is more distinct during 1990-2013 winters (not shown).

We further show the time series of domain-averaged DJF-mean $\mathrm{PV}_{y}$, ECDs, SIC, SAT, and UB frequency over Eurasia and BKS in Fig. 3. While $\mathrm{PV}_{y}$ and SIC (ECDs and SAT) exhibit significant downward (upward) trends during 1979-2013 (Figs. 3a,b), the UB frequency shows only a weak positive trend. However, during
1990-2013 the UB frequency exhibits a modest upward trend (significant at the $90 \%$ confidence level). It could be argued that the increased trend of ECDs is related to the upward trend of the UB frequency. Similarly, the increased trend of cold extremes in East Asia or East Asian cooling could be seen as being connected to the declining trend of the BKS SIC possibly through a decreased $\mathrm{PV}_{y}$ trend associated with the upward trend of BKS warming. Below, we will address these issues by performing composite analyses to examine why the reduction of meridional PV gradient in winter can be due to BKS warming.

\section{c. Is the reduced $P V$ gradient attributed to $B K S$ warming?}

Here, we provide evidence to support the view that the reduction of winter-mean PV gradient is due to BKS warming. To examine the effect of BKS warming on the winter PV gradient, we remove individual UB events to calculate the DJF-mean PV, PV, $\mathrm{Z500}$, and SAT anomalies. In winter the blocking days for each blocking event from lag -10 to 10 days are removed because the blocking duration is generally less than 20 days, where lag 0 denotes the peak day of the UB. Such a removal of UB events can, in a simple way, eliminate the effect of UB on the BKS SIC decline and PV gradient in winter. The BKS warm (cold) winters are 1980,1982, 1983, 1994, 1999, 2004, 2005, 2007, and 2011 (1981, 1986, 1993, 1996, 1997, 1998, 2000, 2002, 2003, 2009, and 2010) based on the $0.5(-0.5)$ standard deviations (STDs) of the normalized detrended BKS SAT time series in Fig. 3b. It is seen that the PV shows a negative anomaly around the BKS (Fig. 4a) when there are positive SAT and Z500 anomalies in the BKS and its adjacent region (Fig. 4e). In contrast, one can find a positive PV anomaly in the BKS and its south and east sides (Fig. 4b) when a cold SAT anomaly dominates the BKS where the Z500 anomaly is negative (Fig. 4f).

Because there are a negative PV anomaly in the high latitudes near BKS and a positive PV anomaly in Eurasian midlatitudes, a reduced meridional PV gradient is inevitably seen to the south of BKS (Fig. 4c). By contrast, there is a large PV gradient over the Eurasian continent (Fig. 4d) because of the PV increase in BKS due to the BKS cooling. This suggests that $\mathrm{PV}_{y}$ tends to become small as the BKS warms up, even when the UB is absent. Thus, the BKS warming can lead to reduced meridional PV gradient in winter. While the positive Z500 anomaly around BKS is mainly produced by winter BKS warming related to the sea ice melting through the surface heat fluxes (mainly sensible heat flux) (Screen and Simmonds 2010), it is not the blocking anomaly because it does not meet the blocking criteria (large amplitude and duration of 10-20 days). The 
Warm BKS winter
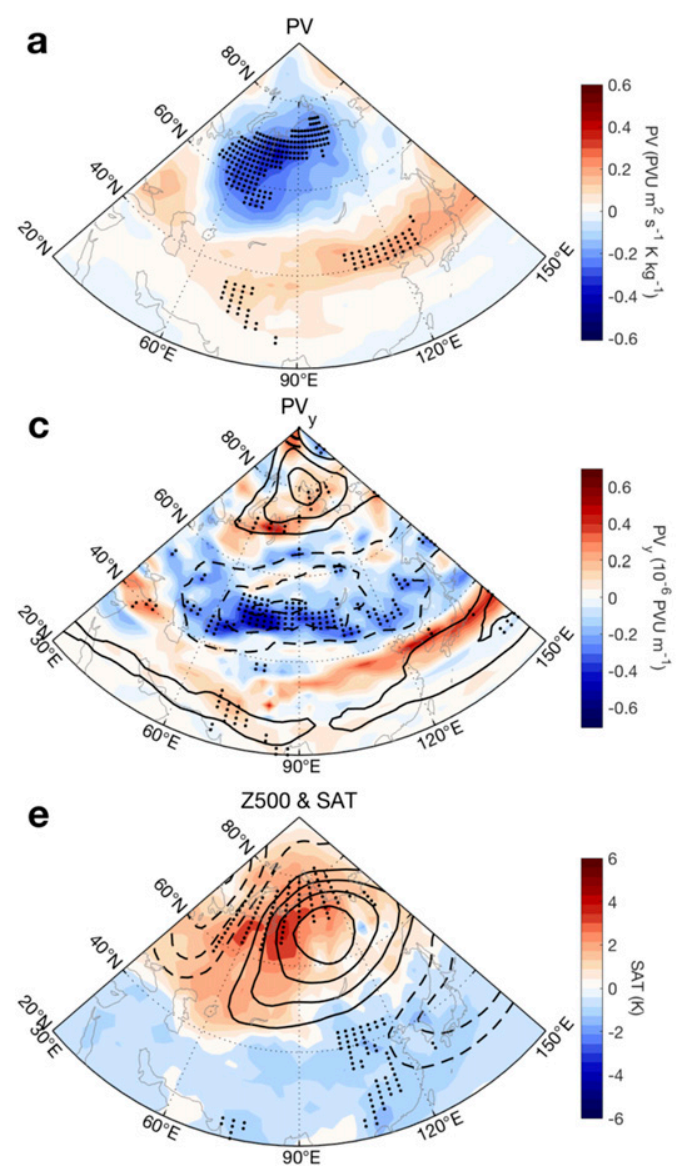

\section{Cold BKS winter}
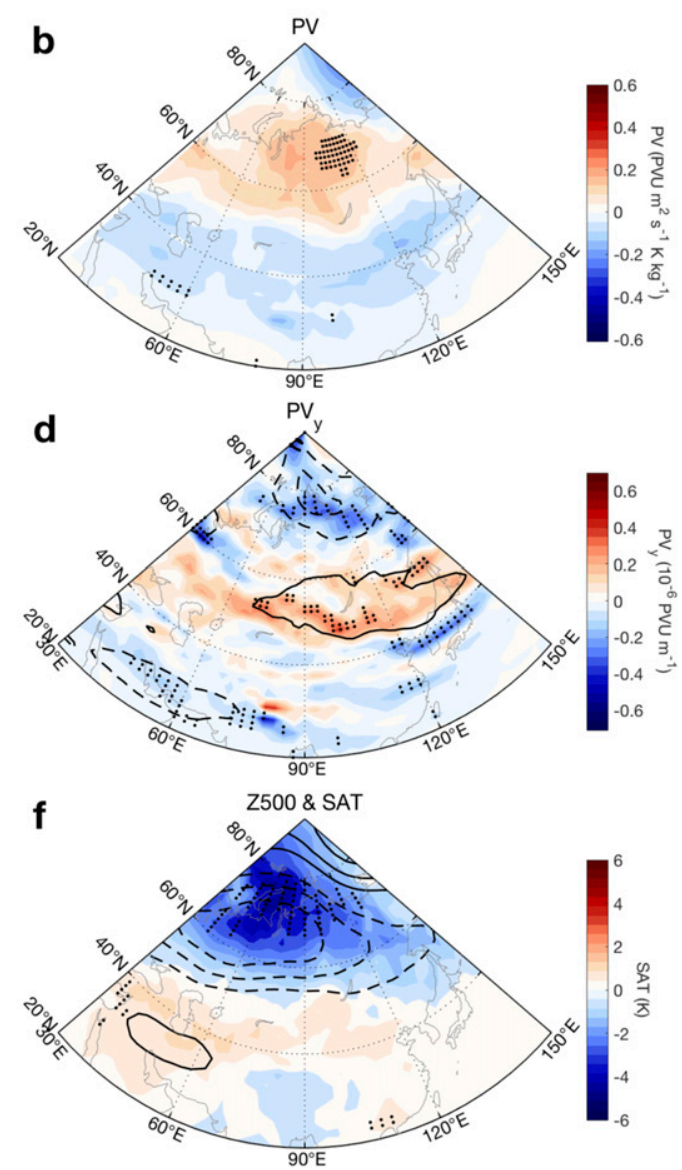

FIG. 4. DJF-mean (a),(b) PV anomaly on the 315-K isentropic surface (color shading), (c),(d) $\mathrm{PV}_{y}$ (color shading) and U500 anomalies $\left(\mathrm{CI}=1.0 \mathrm{~m} \mathrm{~s}^{-1}\right)$, and (e),(f) Z500 (CI =10 gpm) and SAT (color shading) anomalies for UB events excluded (days from lag -10 to 10 days are removed; lag 0 denotes the peak day of UB) in BKS (left) warm and (right) cold winters during 1979-2013. The solid or dashed line denotes a positive or negative anomaly, respectively. The stippling represents the area above the $95 \%$ confidence level for a Monte Carlo test conducted with 5000 simulations.

positive height anomaly and small PV gradient over Eurasia may be considered as a favorable background of $\mathrm{UB}$ events. In brief, a reduced $\mathrm{PV}_{y}$ over Eurasia can be established by the BKS SIC decline via the following sequence: the winter sea ice melting in BKS $\rightarrow$ BKS warming and associated positive Z500 anomaly $\rightarrow$ a negative PV anomaly near BKS $\rightarrow$ reduced meridional PV gradient over midlatitude Eurasia. The study by X. Chen et al. (2018) found that the long-lived and quasistationary UB requires a large SIC decline prior to the UB onset, while the subsequent subseasonal SIC change is related to changes in atmospheric circulation patterns over Eurasia due to associated infrared radiation and surface heat flux changes over BKS (Luo et al. 2017). Thus, it is thought that the small prior PV gradient is mainly generated by the prior sea ice loss in BKS because the amplitude of the UB prior to the blocking onset is weak and a strong prior BKS warming without Eurasian blocking must require a large prior SIC decline.

Although there are negative U500 anomalies in Eurasian midlatitudes and positive U500 anomalies north of $65^{\circ} \mathrm{N}$ for the BKS warming (Fig. 4c), the weakening of mean zonal winds in Eurasian midlatitudes is small (2$3 \mathrm{~m} \mathrm{~s}^{-1}$ ). A similar small intensification of U500 is also seen for BKS cooling (Fig. 4d). Because there is a positive zonal wind anomaly in the East Asia subtropics east of $120^{\circ} \mathrm{E}$ and south of $40^{\circ} \mathrm{N}$ (Fig. 4c), an intensified subtropical jet occurs in East Asia under the BKS warming (not shown). In fact, no midlatitude westerly jet streams are seen in the midlatitude Eurasia from Europe to East Asia (Fig. 1c). Thus, we cannot use the meridional displacement of the westerly jet to examine 

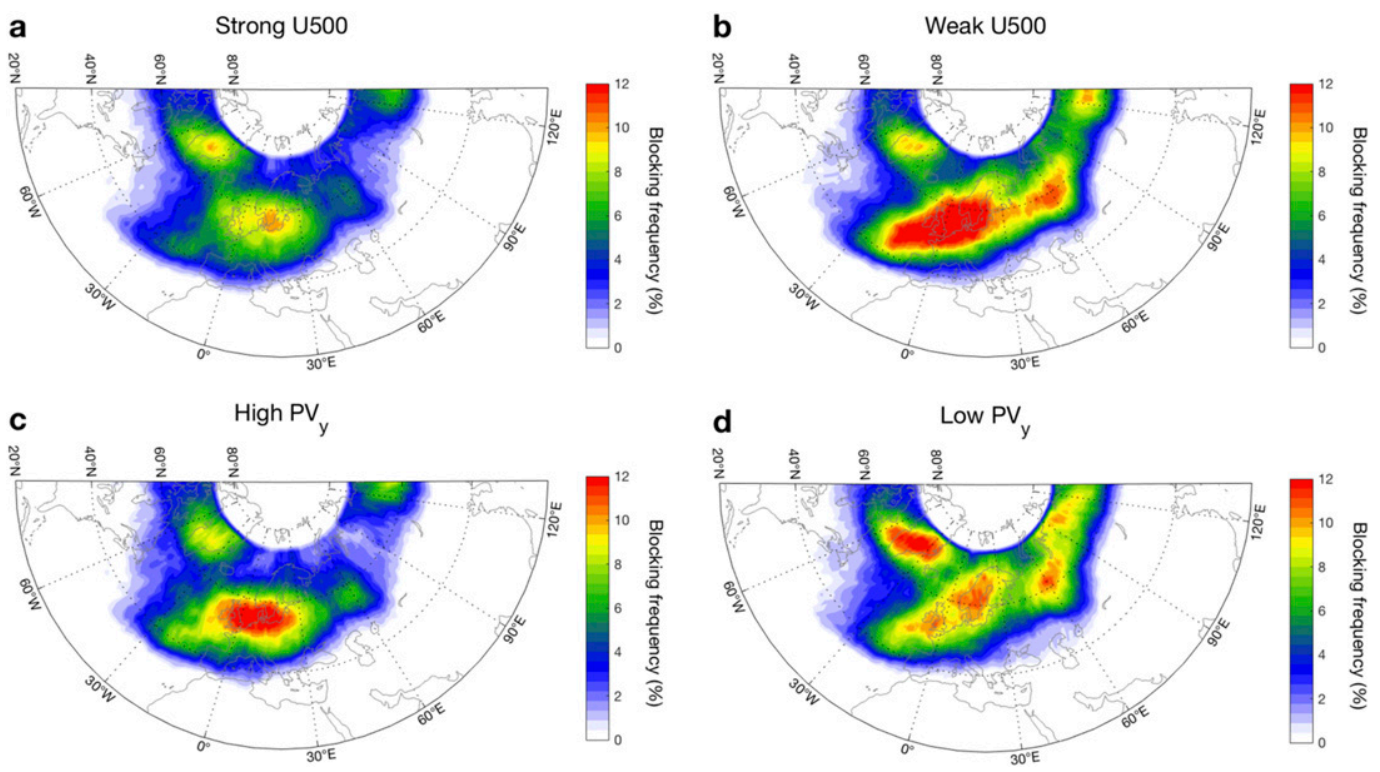

FIG. 5. Horizontal distributions of DJF-mean blocking frequency (\%; color shading) for (a) strong and (b) weak DJF-mean $500-\mathrm{hPa}$ zonal wind (U500) winters averaged over the region $30^{\circ}-90^{\circ} \mathrm{E}, 50^{\circ}-70^{\circ} \mathrm{N}$ and (c) high and (d) low $\mathrm{PV}_{y}$ winters for raw data. The strong (weak) DJF-mean zonal wind winters with $\geq 0.5$ ( $\leq-0.5$ ) STDs of the normalized domain-averaged DJF-mean U500 time series are 1981, 1982, 1986, 1988, 1989, 1992, 1996, 1997, 1998, 1999, 2001, 2003, and 2006 (1979, 1983, 1984, 2004, 2005, 2007, 2009, 2010, 2011, and 2012). The visual display of these $\mathrm{PV}_{y}$ winters can be found in Fig. 6.

how the BKS SIC or warming change affects the UB through inspecting the jet position change, even if the BKS warming can alter the spatial structure and strength of the mean zonal wind in Eurasian midlatitudes near the Ural Mountains and its adjacent region. Although the change in the midlatitude mean zonal wind strength is modest, it seems that there is a large change of its meridional shear from midlatitudes to BKS as the BKS warms (Fig. 4c). Thus, the meridional variation of the mean zonal wind over Eurasia is a main feature of BKS warming. Because $\mathrm{PV}_{y}=\beta-U_{y y}+F U$ in the barotropic limit, the $\mathrm{PV}_{y}$ is an insightful metric because it combines the strength of the mean zonal wind and its nonuniform meridional shear into a single index.

\section{d. Effects of winter-mean zonal wind and PV gradient changes on the Ural blocking frequency distribution}

As noted above, the BKS warming can produce negative DJF-mean U500 and $\mathrm{PV}_{y}$ anomalies in Eurasian midto high latitudes south and east of BKS. Thus, it is useful to examine how the blocking frequency distribution over Eurasia is related to the mean zonal wind and $\mathrm{PV}_{y}$ changes. We define the winter with a small (large) value at least having $-0.5(0.5)$ STDs of DJF-mean $\mathrm{PV}_{y}$ averaged over the Eurasian region $\left(30^{\circ}-90^{\circ} \mathrm{E}, 50^{\circ}-70^{\circ} \mathrm{N}\right)$ as a low (high) $\mathrm{PV}_{y}$ winter. Here, strong (weak) DJF-mean U500 winters are also defined as winters with $\geq 0.5$ $(\leq-0.5)$ STDs of the time series of normalized nondetrended DJF-mean U500 anomaly averaged over the same Eurasian region, which are 1981, 1982, 1986, 1988, 1989, 1992, 1996, 1997, 1998, 1999, 2001, 2003, and 2006 $(1979,1983,1984,2004,2005,2007,2009,2010,2011$, and 2012) (an informative presentation of these high and low $\mathrm{PV}_{y}$ years can be found in Fig. 6 below). We show the two-dimensional blocking frequency distributions in Fig. 5 for strong (weak) DJF-mean U500 and $\mathrm{PV}_{y}$ winters (Fig. 6a). The blocking frequency is higher over the Ural Mountains for a weak mean zonal wind winter (Fig. 5b) than for a strong mean zonal wind winter (Fig. 5a). This indicates that the weak mean zonal wind over Eurasia favors UB. The result is consistent with previous theoretical (Luo 2000) and observational findings (Luo et al. 2016a; Yao et al. 2017), but opposite to the result of the simplified model experiment by Hassanzadeh et al. (2014) where they found lower blocking frequency with reduced equator-to-pole temperature gradient and resulting stronger jet stream. In addition, a higher UB frequency is found for a small PV gradient (Fig. 5d) than for a large PV gradient (Fig. 5c). A notable difference other than the result of the mean zonal wind change is that there is more frequent high-latitude blocking frequency north of $60^{\circ} \mathrm{N}$ between $60^{\circ} \mathrm{E}$ and $120^{\circ} \mathrm{E}$ as the PV gradient is smaller over Eurasia (Fig. 5d). However, we can still see higher high-latitude Ural blocking frequency in the low mean zonal wind winters for detrended data 
a

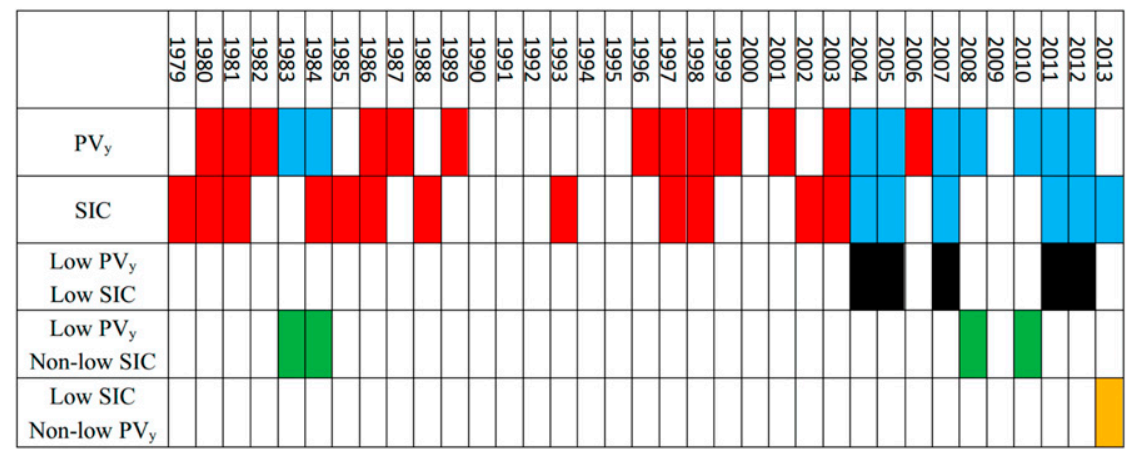

b

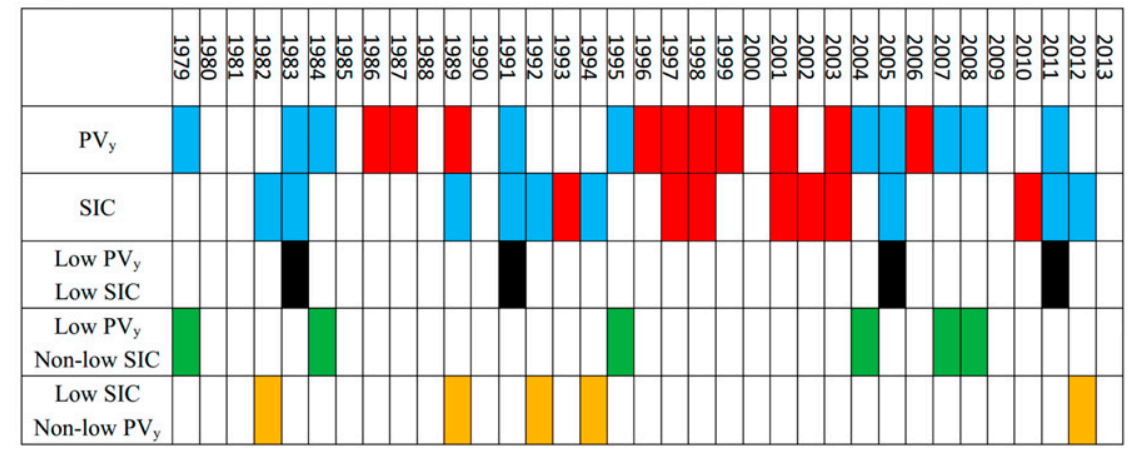

FIG. 6. Numbers of low (blue) and high (red) $\mathrm{PV}_{y}$ and SIC winters, low $\mathrm{PV}_{y}$ winters with low SIC (black), low PV $y$ winters with nonlow SIC (green), and low SIC winters with nonlow $\mathrm{PV}_{y}$ (yellow) during 1979-2013 for (a) nondetrended and (b) detrended data.

(not shown). This means that the mean zonal wind strength index cannot better reflect the trend of highlatitude blocking frequency. This may lead one to conclude that the magnitude of the PV gradient may be used as a better indicator to identify the trend of high-latitude Ural blocking frequency than the mean zonal wind strength. As we can see in Fig. 2b, only the high-latitude blocking frequency shows a linear upward trend during 1979-2013. This trend is more distinct during 1990-2013 than during 1979-89 (not shown). As we will indicate below, the increased trend of the high-latitude Ural blocking frequency or associated Eurasian cold extremes (or Eurasian cooling) is likely related to the downward trend of the winter $\mathrm{PV}_{y}$ over Eurasia.

\section{e. Linkages of midlatitude cold extremes with SIC decline, $P V$ gradient, and UB persistence}

An important issue is whether the midlatitude cold extremes require a large negative SIC anomaly in BKS (i.e., whether such an ice anomaly is a necessary condition for the cold extreme). It is useful to calculate the winter-averaged correlations among ECDs, UB frequency, PV gradient, SIC, and SAT anomalies to establish their linkages. The domain-average $\mathrm{PV}_{y}$ has significant $(p<0.05)$ negative correlations of -0.49 , -0.70 , and -0.81 with the ECDs, BKS SAT, and UB, respectively, and a strong positive correlation of 0.64 with BKS SIC (Table 1). However, we note that the ECDs in East Asia have no significant correlation with the BKS SAT or SIC (Table 1). This could lead to the conclusion that the ECDs in East Asia are not directly linked to the BKS warming and SIC decline, but rather to the decreased PV gradient and hence increased UB frequency. We found similar correlations when the analysis period was restricted to 1990-2013 (Table 2). Conversely, $\mathrm{PV}_{y}$ has no direct correlation with ECDs when the blocking days (from lag -10 to 10 days and lag 0 denotes the peak day) are excluded, while it does correlate with UB frequency, SIC, and SAT (Table 3). This, then, indicates that the PV gradient does not directly influence midlatitude cold extremes or cooling if the UB is absent. In other words, the UB is a bridge of the PV gradient influencing midlatitude cold extremes. Thus, one can deduce that the influence of the BKS SIC decline on winter midlatitude cold extremes is by means of reduced PV gradient and associated blocking change, though the persistence of UB is related to less prior SIC in BKS (Luo et al. 2016a; X. Chen et al. 2018). As 
TABLE 1. Correlation coefficients of domain-averaged $\mathrm{PV}_{y}$ anomaly, extreme cold days, BKS SAT, BKS SIC, and UB frequency during 1979-2013 for nondetrended and detrended (the values in parentheses) data by considering the effective degree of freedom. The $95 \%$ and $99 \%$ confidence levels for a Student's $t$ test are denoted by two and three asterisks, respectively.

\begin{tabular}{|c|c|c|c|c|}
\hline & Extreme cold days & BKS SAT & BKS SIC & UB frequency \\
\hline $\begin{array}{l}\mathrm{PV}_{y} \\
\text { Extreme cold days } \\
\text { BKS SAT } \\
\text { BKS SIC }\end{array}$ & $-0.49^{* * *}\left(-0.41^{* * *}\right)$ & $\begin{array}{c}-0.70^{* * * *}\left(-0.63^{* * * *}\right) \\
0.24(0.09)\end{array}$ & $\begin{array}{c}0.64^{* *}\left(0.54^{* * * *}\right) \\
-0.34(-0.16) \\
-0.86^{* * *}\left(-0.82^{* * *}\right)\end{array}$ & $\begin{array}{c}-0.81^{* * * *}\left(-0.82^{* * * *}\right) \\
0.65^{* * *}\left(0.64^{* * * *}\right) \\
0.51^{* * * *}\left(0.50^{* * *}\right) \\
-0.43\left(-0.45^{* * *}\right)\end{array}$ \\
\hline
\end{tabular}

demonstrated by Luo et al. (2018a), prior to the blocking onset the decrease in $\mathrm{PV}_{y}$ is directly linked to $\mathrm{BKS}$ warming related to the SIC decline. Hence, $\mathrm{PV}_{y}$ is seen as an insightful index for determining the nature of the link between midlatitude cold extremes or continental cooling events and Arctic warming or sea ice decline.

To clarify the key role of the DJF-mean PV gradient in midlatitude cold extremes we classify the SIC and $\mathrm{PV}_{y}$ winters in terms of the time series of normalized domain-averaged winter-mean SIC and $\mathrm{PV}_{y}$. Before the composites of SIC, $\mathrm{PV}_{y}$ and associated atmospheric fields are made, we use the criteria of -0.5 (0.5) STDs of the normalized winter-mean $\mathrm{PV}_{y}$ averaged over the region $\left(30^{\circ}-90^{\circ} \mathrm{E}, 50^{\circ}-70^{\circ} \mathrm{N}\right.$, as above) and SIC anomaly averaged over the BKS $\left(30^{\circ}-90^{\circ} \mathrm{E}, 65^{\circ}-85^{\circ} \mathrm{N}\right)$ to categorize low (high) $\mathrm{PV}_{y}$ and SIC winters and show their classifications in Fig. 6 for nondetrended (Fig. 6a) and detrended (Fig. 6b) cases. It is found that for raw (nondetrended) data there are 13 (12) high $\mathrm{PV}_{y}$ (SIC) winters during 1979-2013 (red color in Fig. 6a) and there are 9 (6) low $\mathrm{PV}_{y}$ (SIC) winters (blue color in Fig. 6a). We further found 5 low SIC winters (below -0.5 STD) with low $\mathrm{PV}_{y}$ (black color in Fig. 6a), 4 low $\mathrm{PV}_{y}$ winters with nonlow SIC (above -0.5 STD) (green color in Fig. 6a), and 1 low SIC winter with nonlow $\mathrm{PV}_{y}$ (2013) (yellow color in Fig. 6a). For detrended data, we found 10 (7) high $\mathrm{PV}_{y}$ (SIC) winters (red color in Fig. 6b) and 10 (9) low $\mathrm{PV}_{y}$ (SIC) winters (blue color in Fig. 6b) during 1979-2013. For this case, there are also 4 low SIC winters with low PV gradient (below -0.5 STDs) (black color in Fig. 6b), 6 low PV gradient winters (below -0.5 STD) with nonlow SIC (above -0.5 STD) (green color in Fig. 6b), and 5 low SIC winters (below -0.5 STD) with nonlow PV gradient (above -0.5 STD) (yellow color in Fig. 6b) during 1979-2013. A comparison between detrended and nondetrended statistical results reveals that the low $\mathrm{PV}_{y}$ does not require that the SIC must be low in BKS on an interannual time scale (detrended case), but the low SIC dominates low $\mathrm{PV}_{y}$ for the case with trend. This means that while the SIC trend mainly determines the trend of $\mathrm{PV}_{y}$, the interannual (year to year) change of $\mathrm{PV}_{y}$ is related not only to the interannual variability of the BKS SIC, but also to other factors, including internal atmospheric variability.

The composites show that midlatitude Eurasian cold extremes are more intense and cover a larger domain for low $\mathrm{PV}_{y}$ winters with low SIC (Fig. 7c) than those for low $\mathrm{PV}_{y}$ winters with nonlow SIC (Fig. 7d) because of much stronger BKS warming (Fig. 7e). Correspondingly, the height anomaly shows a UB with a positive NAO $\left(\mathrm{NAO}^{+}\right.$) (Fig. 7a) related to smaller $\mathrm{PV}_{y}$ (see Fig. S1a in the online supplemental material) and larger SIC decline (Fig. S1c), but for a composite in low $\mathrm{PV}_{y}$ winters with nonlow SIC (Fig. 7b) a UB with $\mathrm{NAO}^{-}$or an eastward-displaced $\mathrm{NAO}^{-}$is seen and related to weak negative SIC anomaly (Fig. S1d) and low PV (Fig. S1b). While the large BKS SIC decline favors cold extremes over Eurasia, intense cold extremes (Fig. 7d) are still observed in the absence of large negative SIC anomaly (Fig. S1d). The cause and effect linkage between the atmospheric circulation pattern, BKS warming, and SIC changes has been examined in Luo et al. (2017) using daily composites and in Zhong et al. (2018). They found that under $\mathrm{NAO}^{-}\left(\right.$or $\mathrm{AO}^{-}$) conditions the intrusion of warm moist air to the BKS is suppressed and one does not observe a large BKS SIC decline (Fig. S1d). While $\mathrm{UB}$ with an $\mathrm{NAO}^{+}$(Fig. 7a) favors a large SIC decline in BKS (Fig. S1c), it must require a large negative SIC anomaly prior to the blocking onset. Below, we further examine the interannual variabilities of $\mathrm{PV}_{y}$, SIC, atmospheric circulation pattern and cold extremes and their possible linkages.

TABLE 2. As in Table 1, but during 1990-2013 and the 90\% confidence level for a Student's $t$ test is denoted by one asterisk.

\begin{tabular}{|c|c|c|c|c|}
\hline & Extreme cold days & BKS SAT & BKS SIC & Blocking frequency \\
\hline $\begin{array}{l}\mathrm{PV}_{y} \\
\text { Extreme cold days } \\
\text { BKS SAT } \\
\text { BKS SIC }\end{array}$ & $-0.51^{* * *}(-0.34)$ & $\begin{array}{c}-0.74^{* * * *}\left(-0.66^{* * * *}\right) \\
0.27(-0.07)\end{array}$ & $\begin{array}{c}0.73^{* *}\left(0.64^{* * * *}\right) \\
-0.42(-0.11) \\
-0.88^{* * * *}\left(-0.83^{* * * *}\right)\end{array}$ & $\begin{array}{c}-0.88^{* * * *}\left(-0.86^{* * * *}\right) \\
0.61^{* * * *}\left(0.52^{* * *}\right) \\
0.56^{* *}\left(0.47^{* * *}\right) \\
-0.56^{*}\left(-0.45^{* *}\right)\end{array}$ \\
\hline
\end{tabular}


TABLE 3. Correlation coefficients of domain-averaged $\mathrm{PV}_{y}$ anomaly for the blocking days excluded with domain-averaged PVy anomaly with blocking days, extreme cold days, BKS SAT, BKS SIC, and UB frequency during 1979-2013 and 1990-2013 for nondetrended and detrended (the values in parentheses) data by considering the effective degree of freedom. The $90 \%, 95 \%$, and $99 \%$ confidence levels for a Student's $t$ test are respectively denoted by one, two, and three asterisks.

\begin{tabular}{cccccc}
\hline \hline & $\mathrm{PV}_{y}$ & Extreme cold days & BKS SAT & BKS SIC & Blocking frequency \\
\hline $1979-2013$ & $0.75^{* * * *}\left(0.70^{* * * *}\right)$ & $-0.29(-0.12)$ & $-0.62^{* * * *}\left(-0.49^{* * * *}\right)$ & $0.64^{* * * *}\left(0.43^{* * *}\right)$ & $-0.41^{*}\left(-0.40^{* * *}\right)$ \\
$1990-2013$ & $0.83^{* * * *}\left(0.78^{* * * *}\right)$ & $-0.43^{*}(-0.16)$ & $-0.68^{* * * *}\left(-0.54^{* * * *}\right)$ & $0.67^{* * * *}\left(0.51^{* * *}\right)$ & $-0.65^{* * * *}\left(-0.58^{* * * *}\right)$ \\
\hline
\end{tabular}

For the above cases, the composites of Z500 and SAT anomalies, cold extreme days, and air temperature anomaly averaged over $30^{\circ}-90^{\circ} \mathrm{E}$ are shown in Fig. 8 for detrended data. Intense widespread cold extremes occur in the Eurasian continent (Fig. 8e) if $\mathrm{PV}_{y}$ is small and when the continental cooling shifts toward high latitudes, even if the negative SIC anomaly and associated warming are less strong (Fig. 8h). An eastward-displaced $\mathrm{NAO}^{-}$-like pattern (Fig. 8b) is also instrumental in the generation of the cold East Asian extremes. For low $\mathrm{PV}_{y}$ winters with low SIC, the outbreak of Eurasian cold extremes is associated with a UB with $\mathrm{NAO}^{+}$(Fig. 8a). It is of central importance that there are no intense cold extremes in midlatitude Eurasia (Fig. 8f) in the presence of large negative SIC anomaly, if $\mathrm{PV}_{y}$ is large. This case corresponds to a widespread warming over Eurasian continent (Figs. 8c,i) and an eastward-displaced $\mathrm{NAO}^{+}$(Fig. 8c). It appears that the magnitude of the DJF-mean PV gradient may play the central role in the generation of midlatitude cold extremes. Large SIC decline can influence the occurrence of midlatitude cold extremes, but only when the PV gradient is small.

We now examine the difference of the UB and SAT extreme between low and high $\mathrm{PV}_{y}$ winters. For detrended data there are 21 (12) UB events in low (high) $\mathrm{PV}_{y}$ winters during 1979-2013. To understand how the UB changes between the high and low $\mathrm{PV}_{y}$, we show the time-longitude evolution of composite daily Z500 anomalies averaged over the region $\left(50^{\circ}-70^{\circ} \mathrm{N}\right)$ based on $\mathrm{UB}$ events in the high and low $\mathrm{PV}_{y}$ winters shown in Figs. 9a and 9b, respectively. For low $\mathrm{PV}_{y}$, the UB is immobile during its life cycle and can last long time (Fig. 9b), but has a short lifetime and moves rapidly westward after its peak for high $\mathrm{PV}_{y}$ (Fig. 9a). This suggests that the UB is more stationary and has a longer duration in low $\mathrm{PV}_{y}$ winters than in high $\mathrm{PV}_{y}$ winters because it easily satisfies $C_{\mathrm{NP}} \approx 0$ and is in a nearly nondispersion $\left(C_{g p} \approx 0\right)$ region in the low $\mathrm{PV}_{y}$ winters. The mean durations of composite UB events in high and low $\mathrm{PV}_{y}$ winters are 9.5 and 15.5 days, respectively (Figs. 9a,b) as the duration of the UB is defined as the number of consecutive days for which the daily domain-averaged Z500 anomaly exceeds $100 \mathrm{gpm}$. These differences are statistically significant ( $p<0.05$; Monte Carlo test). Thus, a significant increase in the UB duration is linked to the reduction of the PV gradient over Eurasia. A similar result is also found for the nondetrended data (not shown).

It is useful to investigate the frequency distribution of daily SAT anomalies averaged over the region $60^{\circ}-$ $120^{\circ} \mathrm{E}, 40^{\circ}-60^{\circ} \mathrm{N}$ and the blocking frequency (\%) averaged over the latitudes $40^{\circ}-75^{\circ} \mathrm{N}$ along the longitude in Figs. $9 \mathrm{c}$ and $9 \mathrm{~d}$ in low and high $\mathrm{PV}_{y}$ winters for the detrended data. The distribution of daily SAT anomalies in Eurasian midlatitudes shows a shift to the cold side for low values of $\mathrm{PV}_{y}$ (Fig. 9c), a result consistent with the significant increase in UB frequency (blocking days) over Eurasian continent near the Ural Mountains (Fig. 9d). Obviously, the increased UB frequency in a low $\mathrm{PV}_{y}$ winter (Fig. 9d) is related to the increased persistence of UB (Fig. 9b). Similar results are also found for raw data (not shown). Hence, the reduction of $\mathrm{PV}_{y}$ favors cold extremes over Eurasia due to increased UB frequency by increased UB persistence (Fig. 9b). Thus, we conclude that the small PV gradient or weakened PV barrier is a key transmission factor for the generation of midlatitude cold extremes through increasing the persistence of UB.

\section{Causal linkage between Ural blocking and PV gradient changes}

Because the PV gradient, UB, and SIC changes are coupled together and related to each other during the blocking life cycle, the above trend and composite analyses cannot unambiguously identify the causal relation between these parameters. To verify whether a small PV gradient causes a long-lived UB, it is useful to calculate the magnitude and spatial distribution of $\mathrm{PV}_{y}$ during the mature and prior periods of UB and its relationship with the BKS SIC and warming from a daily composite. Such a treatment has a theoretical basis, as described below.

From Eqs. (5a)-(5c), we can obtain the time-dependent $\mathrm{PV}$ gradient $\left(\mathrm{PV}_{y}\right)_{\text {life }}=\mathrm{PV}_{y}+\mathrm{PV}_{y}\left(U_{m}\right)$ during the blocking life cycle, where $\mathrm{PV}_{y}$ represents the background or prior $\mathrm{PV}$ gradient and $\mathrm{PV}_{y}\left(U_{m}\right)=-\left(U_{m}\right)_{y y}+$ 
Low $\mathrm{PV}_{\mathrm{y}}$ winter with low SIC
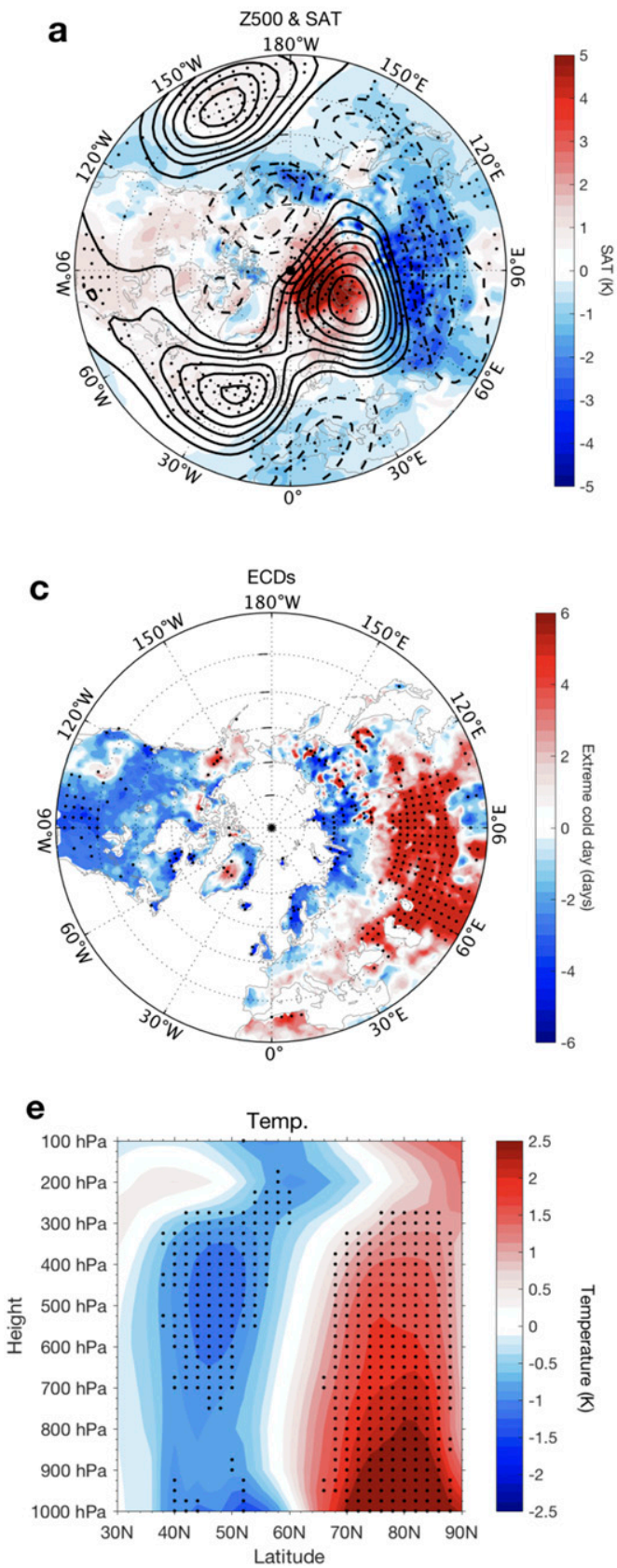

Low $\mathrm{PV}_{\mathrm{y}}$ winter
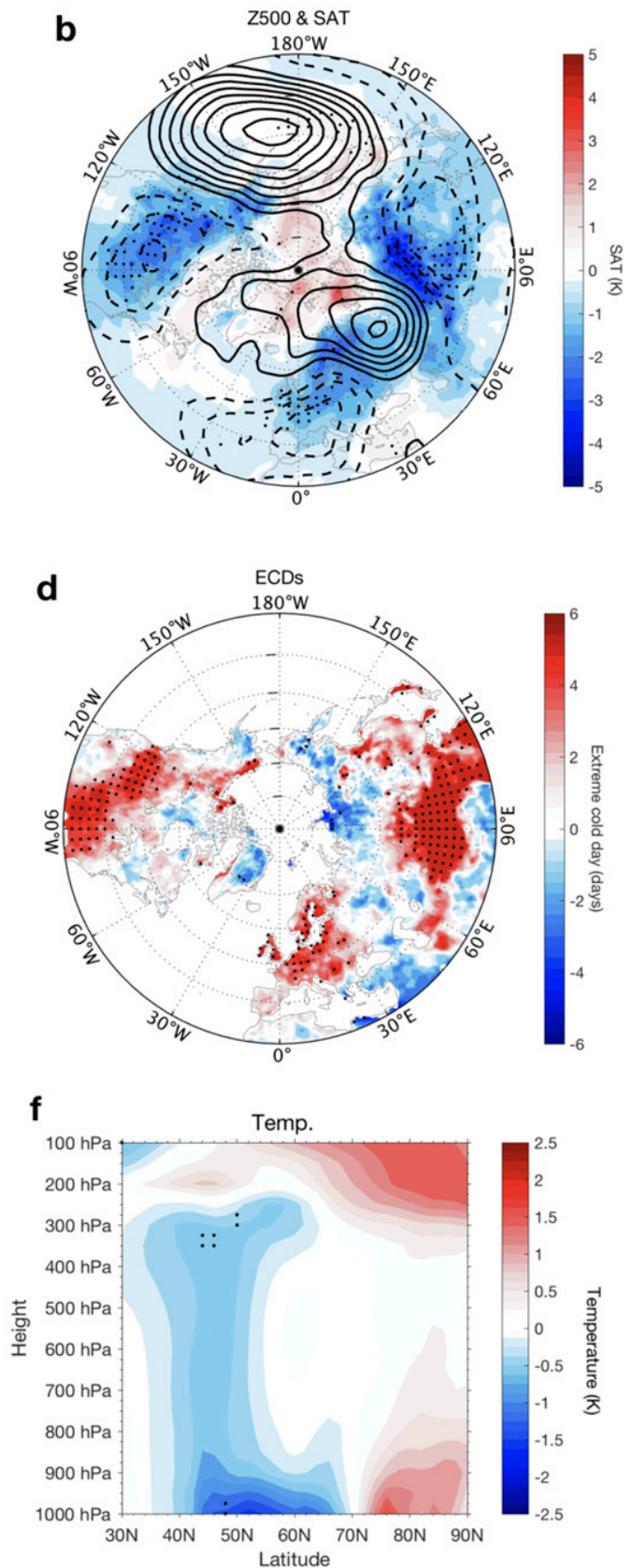

FIG. 7. Composites of DJF-mean (a),(b) Z500 (contours) and SAT anomalies, (c),(d) ECDs, and (e),(f) temperature (labeled temp.) anomaly averaged over $30^{\circ}-90^{\circ} \mathrm{E}$ for (left) both low SIC and low PV gradient winters below -0.5 STDs $(2004,2005,2007,2011,2012)$ and (right) low PV gradient winters below -0.5 STD with nonlow SIC above -0.5 STD $(1983,1984,2008,2010)$ for nondetrended data. The stippling indicates regions over which the differences are significantly different from zero $(p<0.05)$ based on a 5000-simulation Monte Carlo test.

$F U_{m}\left(U_{m}=-\partial \psi_{m} / \partial y\right)$ is the PV gradient change due to the mean zonal wind $\left(U_{m}\right)$ change during the blocking life cycle. There is $\left(\mathrm{PV}_{y}\right)_{\text {life }}=\mathrm{PV}_{y}+\mathrm{PV}_{y}\left(U_{m}\right) \approx \mathrm{PV}_{y}$ during the prior period of blocking (prior to the blocking onset) because of the blocking amplitude being small and $\mathrm{PV}_{y}\left(U_{m}\right) \approx 0$. Thus, the background $\mathrm{PV}$ gradient $\mathrm{PV}_{y}$ can be obtained approximately by calculating the time mean of $\left(\mathrm{PV}_{y}\right)_{\text {life }}$ over the prior period of blocking. The 


\section{Low $\mathrm{PV}_{\mathrm{y}}$ winter with low SIC}
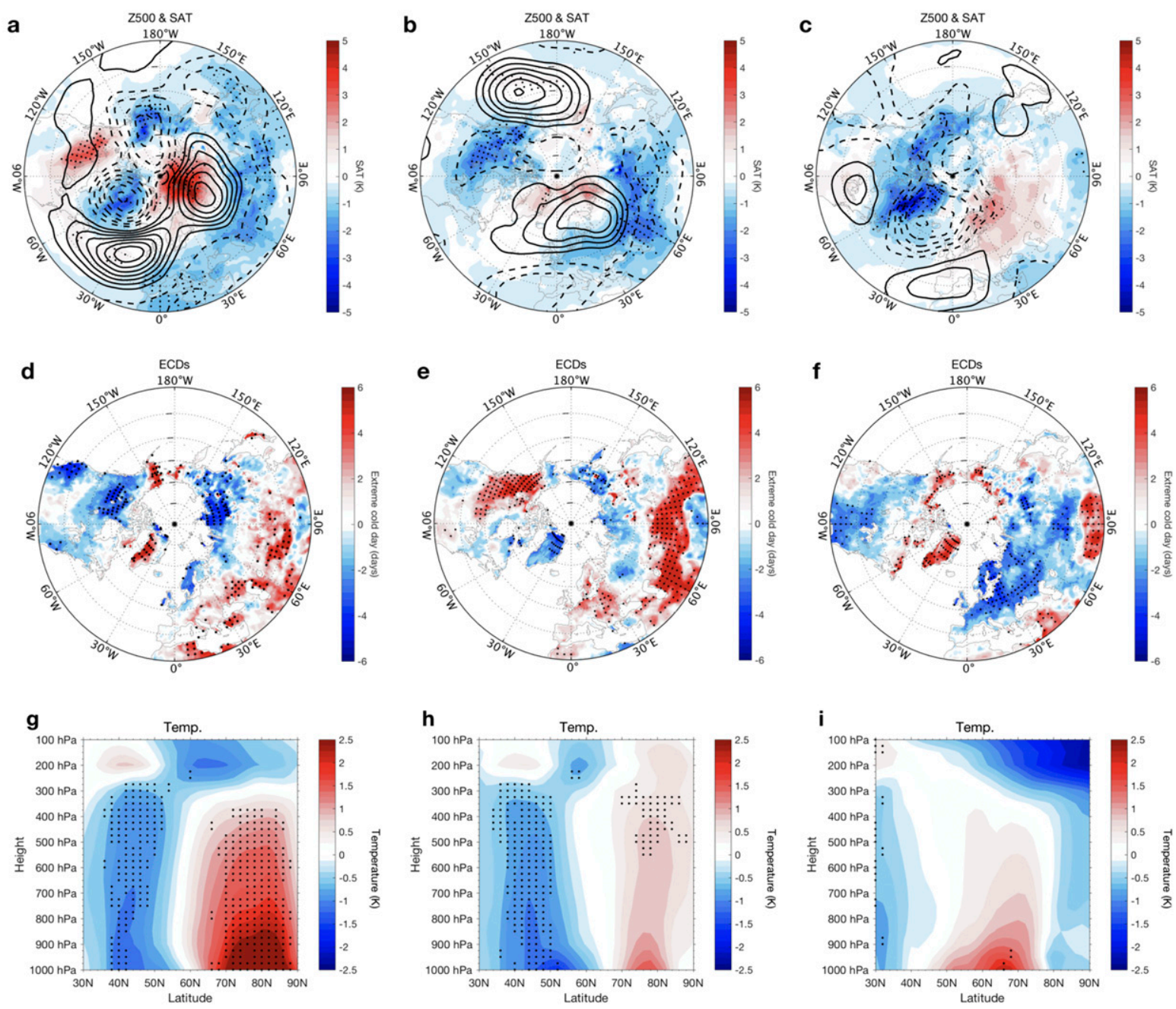

FIG. 8. Composites of (a)-(c) Z500 (contours) and SAT anomalies, (d)-(f) extreme cold days, and (g)-(i) temperature anomaly averaged over $30^{\circ}-90^{\circ} \mathrm{E}$ for (left) both low SIC and low PV gradient winters below -0.5 STD $(1983,1991,2005,2011)$, (center) low PV gradient winters below -0.5 STD with nonlow SIC above -0.5 STD $(1979,1984,1995,2004,2007,2008)$, and (right) low SIC winters below -0.5 STD with nonlow PV gradient above -0.5 STD $(1982,1989,1992,1994,2012)$ for the detrended data. The stippling is as in Fig. 7.

result of the NMI model shows that when $\mathrm{PV}_{y}$ is small, the blocking is both strong and long-lived and then leads to a smaller $\mathrm{PV}_{y}$ within the blocking region during the blocking episode (not shown). In contrast, the blocking is weak and short-lived as $\mathrm{PV}_{y}$ is large (not shown). Thus, the small prior $\mathrm{PV}$ gradient is a prerequisite for long-lived blocking, even if this blocking leads to a smaller PV gradient within the blocking region (not shown). This theoretical result is not presented here, which will be reported in another paper. Thus, it is useful to calculate the time-mean $\mathrm{PV}_{y}$ anomalies and associated Z500, SAT, and SIC anomaly fields over the mature and prior periods of UB. We first show the time-mean composite daily Z500 and SAT, $\mathrm{PV}_{y}$, and SIC anomalies averaged over the blocking mature period (from lag -5 to 5 days) of UB events in low and high $\mathrm{PV}_{y}$ winters in Fig. 10. In low $\mathrm{PV}_{y}$ winters the $\mathrm{Z} 500$ anomaly shows a high-latitude wave train that consists of the UB and $\mathrm{NAO}^{+}$(Luo et al. 2016a; Kelleher and Screen 2018) and a strong widespread cooling over Eurasia from West Asia to East Asia (Fig. 10b). But in a high $\mathrm{PV}_{y}$ winter one can observe a midlatitude wave train from North Atlantic to BKS through Europe as noted in Zhong et al. (2018) and a weak eastward-displaced cold anomaly over Eurasia (Fig. 10a). Clearly, the generation of the strong widespread Eurasian cooling (Fig. 10b) is associated with a strong negative $\mathrm{PV}_{y}$ anomaly over Eurasia (Fig. 10d) and a large negative SIC anomaly in BKS (Fig. 10f). 

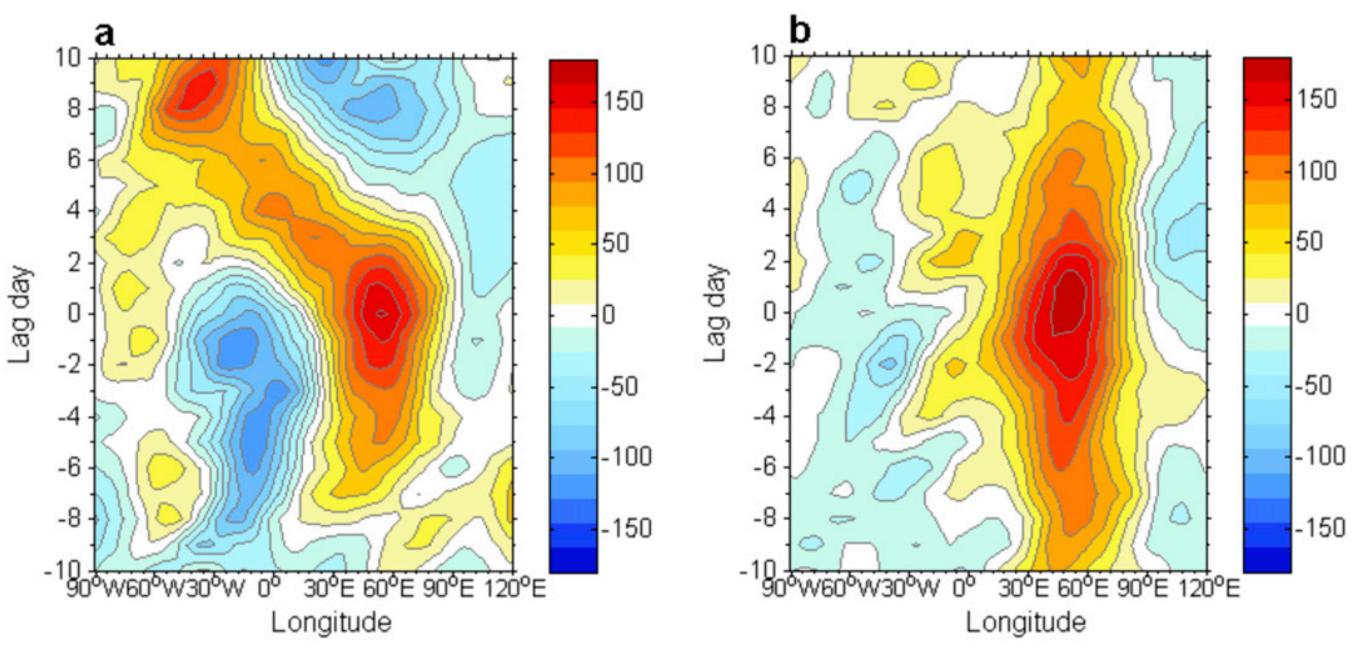

C

\section{d}
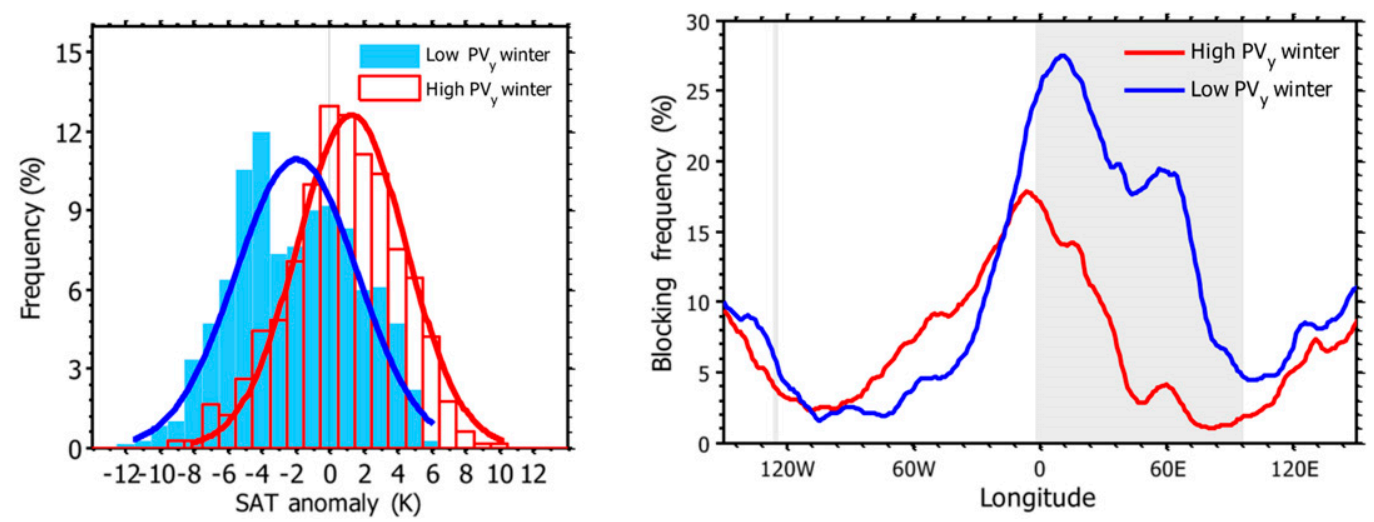

FIG. 9. Time-longitude evolution of composite daily Z500 anomalies averaged over $50^{\circ}-70^{\circ} \mathrm{N}$ for UB events based on the 1D blocking index for (a) high and (b) low PV $\mathrm{PV}_{y}$ winters; the frequency distribution of (c) daily SAT anomalies averaged over the region $60^{\circ}-120^{\circ} \mathrm{E}, 40^{\circ}-60^{\circ} \mathrm{N}$ and (d) latitude-averaged blocking frequency $(\%)$ in the latitude band $40^{\circ}-75^{\circ} \mathrm{N}$ along the longitude for high (red line) and low (blue line) $\mathrm{PV}_{y}$ winters for the detrended data. The thick red and blue lines in (c) represent the probability density function, and the gray shading in (d) denotes the low-minus-high $\mathrm{PV}_{y}$ difference being significant at the $95 \%$ confidence level for a Monte Carlo test conducted with 5000 simulations.

However, in the high $\mathrm{PV}_{y}$ winter the UB is short-lived and the East Asian cooling is relatively weak (Fig. 10a), which requires that the negative $\mathrm{PV}_{y}$ anomaly is weak over Eurasia (Fig. 10c) with the negative SIC anomaly being small in BKS (Fig. 10e). Because the UB is longlived in the low $\mathrm{PV}_{y}$ winter and vice versa (Figs. 9a,b), we see that the long-lived UB corresponds to a smaller PV gradient within the blocking region (Fig. 10d) than the short-lived UB (Fig. 10c).

Here, we demonstrate that the duration or persistence of UB depends strongly on the magnitude of prior (or background) PV gradient over Eurasian mid- to high latitudes. We show time-mean Z500, SAT, SIC, and $\mathrm{PV}_{y}$ anomaly fields averaged over the prior period (from lag -30 to -20 days) of UB in Fig. 11. It is seen that prior to blocking onset (from lag -30 to -20 days), a large negative SIC anomaly still appears in BKS (Fig. 11f), even if the UB is absent (Fig. 11b). An evident wave train occurring together with a $\mathrm{NAO}^{+}$coming from the North Atlantic is still seen in Fig. 11b. For this case, a positive Z500 anomaly appears in high-latitude Siberia, which is intensified by the prior BKS SIC decline (Fig. 11f) through warming. Moreover, there is a weak cooling over Siberia (Fig. 11b) and a negative prior $\mathrm{PV}_{y}$ anomaly appears in East Asia (Fig. 11d). The prior $\mathrm{PV}_{y}$ anomaly has a spatial structure with a tripolar structure similar to Fig. 4c. In contrast, when the prior SIC anomaly in BKS is positive (Fig. 11e), the prior PV gradient is slightly intensified in the region from the Ural Mountains to East Asia (Fig. 11c) through Eurasian 


\section{High $\mathrm{PV}_{\mathrm{y}}$ winter}
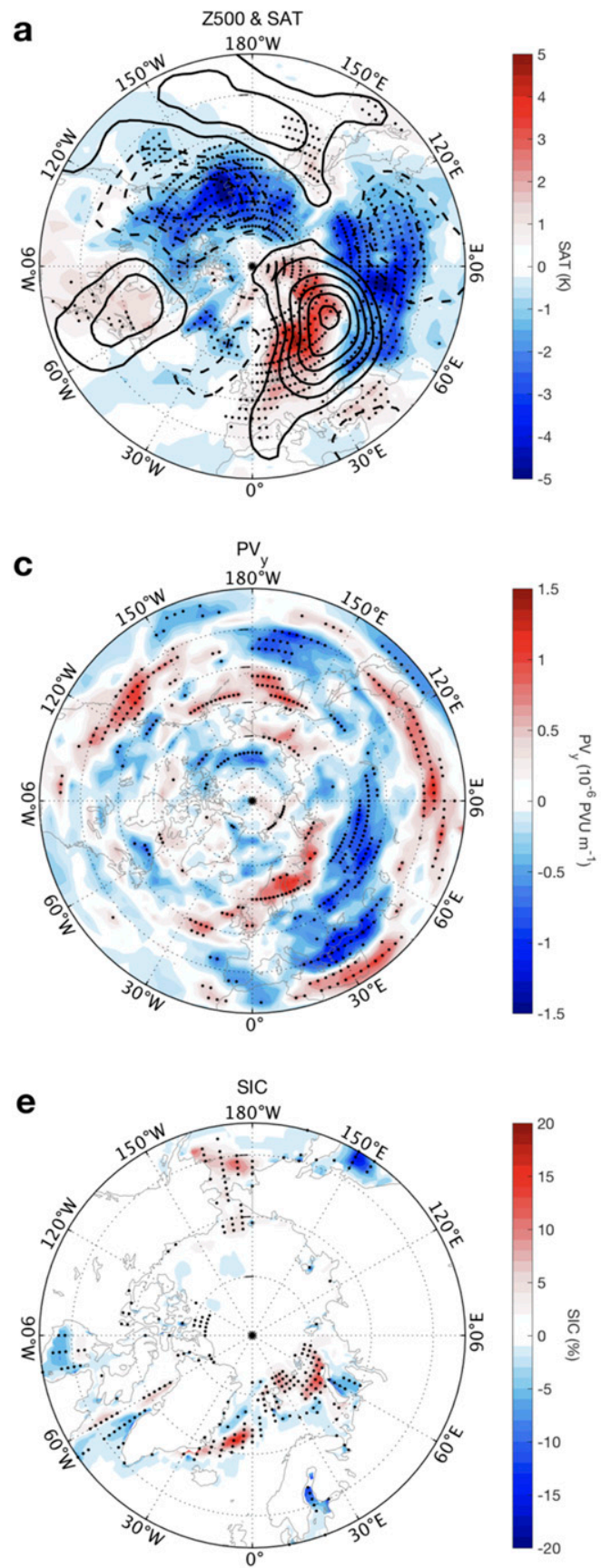

\section{Low $\mathrm{PV}_{\mathrm{y}}$ winter}
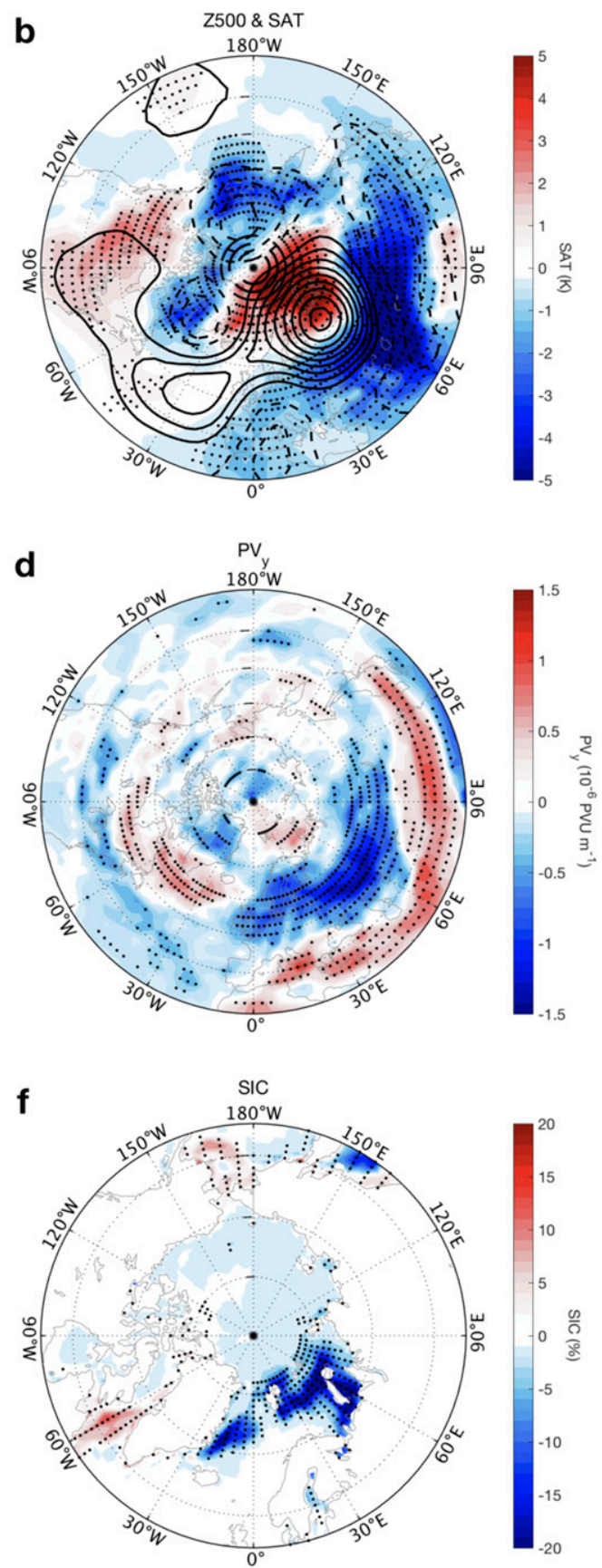

FIG. 10. Time-mean composite daily (a),(b) Z500 (CI = $20 \mathrm{gpm}$ ) and SAT (color shading), (c),(d) PV gradient, and (e),(f) SIC anomalies averaged from lag -5 to 5 days for UB events in (left) high- and (right) low-detrended$\mathrm{PV}_{y}$ winters. The stippling is as in Fig. 7.

continental warming (Fig. 11a). Thus, the presence of a positive prior temperature or height anomaly in the high-latitude Ural-Siberia region due to a prior BKS SIC decline can lead to a reduced prior $\mathrm{PV}_{y}$ over
Eurasia. The $\mathrm{PV}_{y}$ is smaller for long-lived UB (Fig. 11d) than for short-lived UB (Fig. 11c). To some extent, the large prior SIC decline or associated PV gradient reduction may be thought of as being a precursor of 


\section{High $\mathrm{PV}_{\mathrm{y}}$ winter}
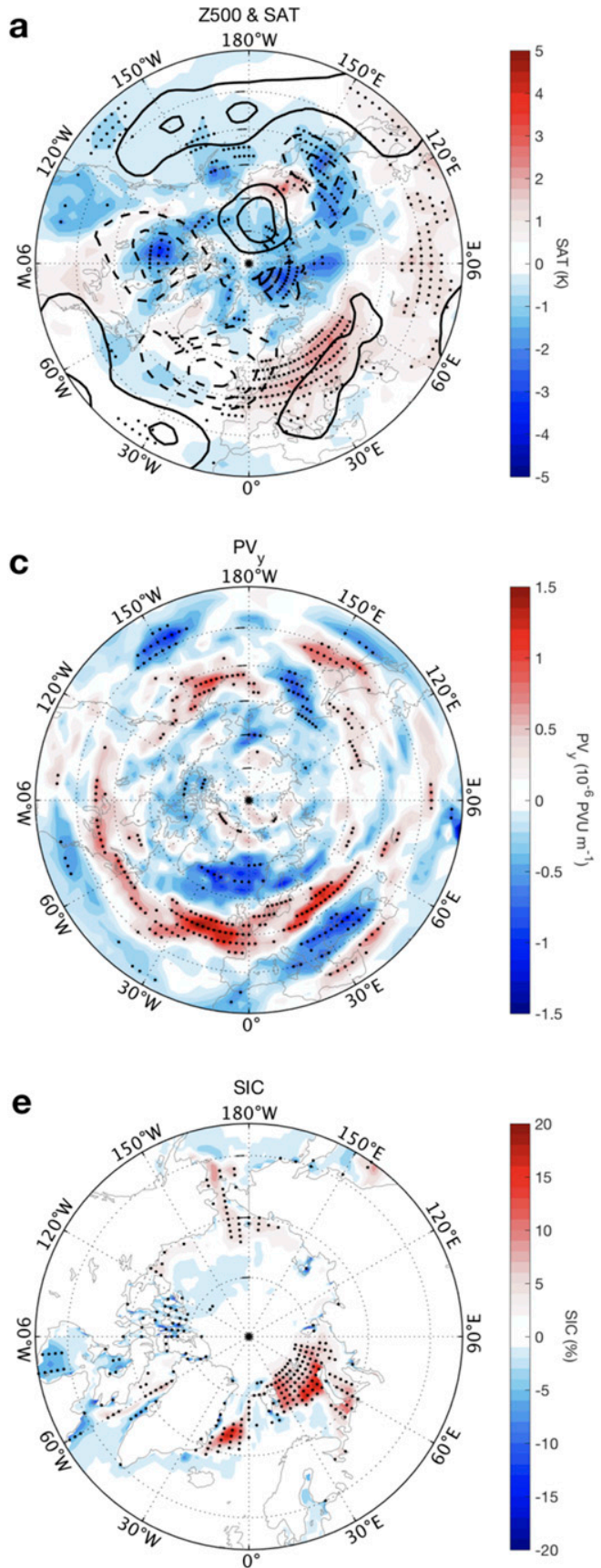

\section{Low $\mathrm{PV}_{\mathrm{y}}$ winter}
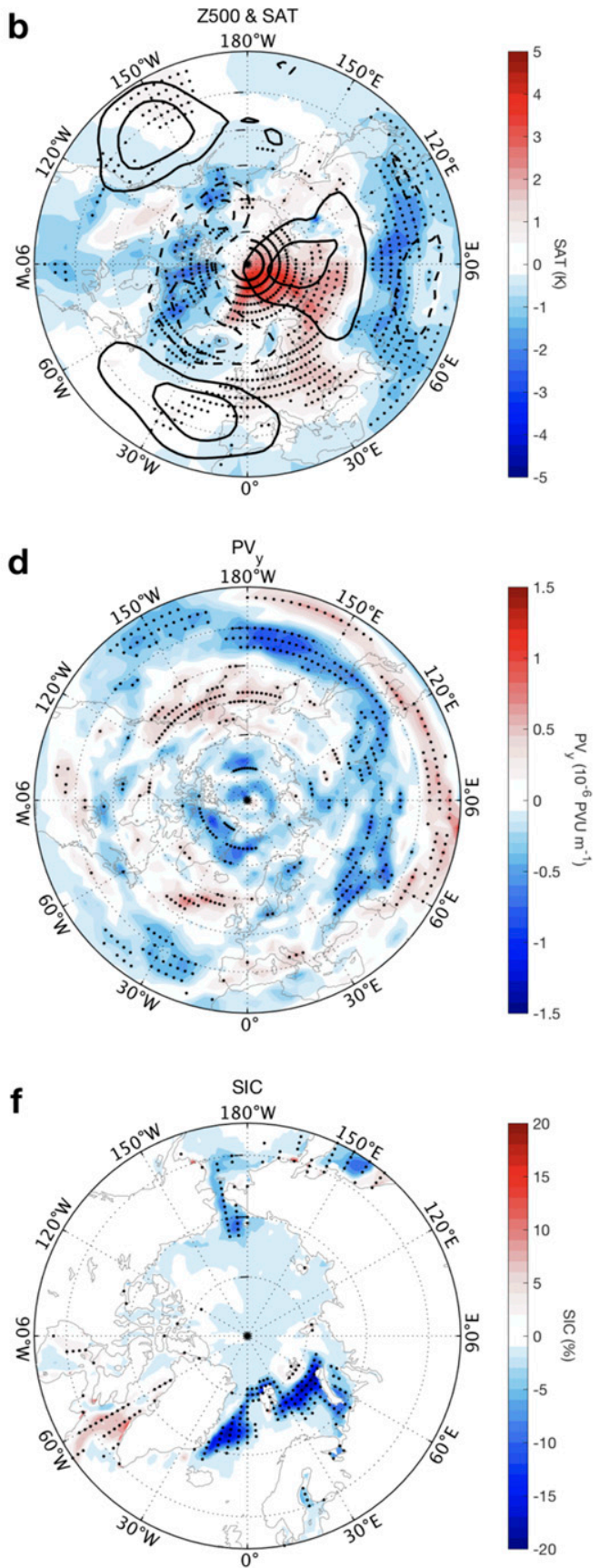

FIG. 11. As in Fig. 10, but for the time mean from lag -30 to -20 days.

long-lived UB events, though there is a positive feedback between the BKS SIC decline and UB persistence in winter as the UB occurs.

To further substantiate our assertion that a small PV gradient has existed before a long-lived UB occurs and it is linked to a prior SIC decline, it is useful to examine the time variations of domain-averaged composite daily Z500 anomaly over $\left(30^{\circ}-90^{\circ} \mathrm{E}, 50^{\circ}-75^{\circ} \mathrm{N}\right)$ (the UB intensity), BKS SIC and SAT anomalies over the BKS, SAT anomaly over Siberia or East Asia $\left(60^{\circ}-120^{\circ} \mathrm{E}, 40^{\circ}-\right.$ $\left.60^{\circ} \mathrm{N}\right)$ and $\mathrm{PV}_{y}$ anomaly over the region $\left(30^{\circ}-90^{\circ} \mathrm{E}, 50^{\circ}-\right.$ $70^{\circ} \mathrm{N}$ ) during the UB life cycle in low and high $\mathrm{PV}_{y}$ 

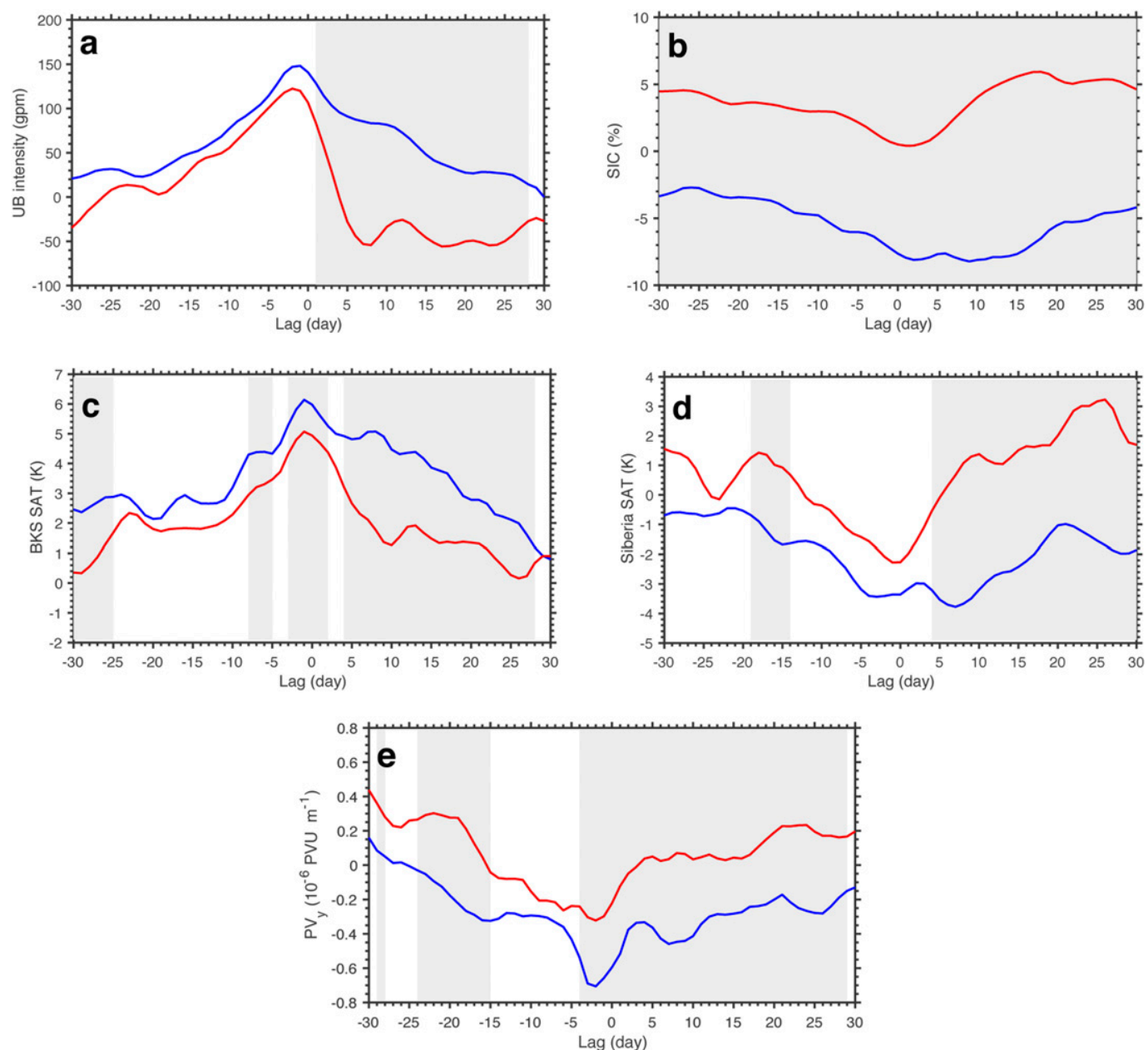

FIG. 12. Time series of composite daily (a) domain-averaged UB intensity over $30^{\circ}-90^{\circ} \mathrm{E}$ and $55^{\circ}-75^{\circ} \mathrm{N}$; (b) BKS SIC and (c) BKS SAT anomalies over the region $30^{\circ}-90^{\circ} \mathrm{E}, 65^{\circ}-85^{\circ} \mathrm{N}$, (d) Siberian SAT anomaly in the region $60^{\circ}-$ $120^{\circ} \mathrm{E}, 40^{\circ}-60^{\circ} \mathrm{N}$, and (e) $\mathrm{PV}_{y}$ anomaly over the region $30^{\circ}-90^{\circ} \mathrm{E}, 50^{\circ}-70^{\circ} \mathrm{N}$ for 12 and $21 \mathrm{UB}$ events in high (red line) and low (blue line) $\mathrm{PV}_{y}$ winters for the detrended data during 1979-2013. The gray shading denotes the 95\% confidence level for a Monte Carlo test conducted with 5000 simulations.

winters. Figure 12 shows that the UB has larger amplitude and a longer lifetime in the low $\mathrm{PV}_{y}$ winter than in the high $\mathrm{PV}_{y}$ winter (Fig. 12a), in agreement with the result in Figs. 9a and 9b. This blocking decays rapidly in a high $\mathrm{PV}_{y}$ winter (red line in Fig. 12a), but persists for a longer time in a low $\mathrm{PV}_{y}$ winter (blue line in Fig. 12a). During the prior period (from lag -30 to -10 days) of UB, the blocking amplitude is small and does not show a significant time variation (Fig. 12a). Even so, the prior amplitude of the long-lived UB in the low $\mathrm{PV}_{y}$ winter is also larger than that of short-lived $\mathrm{UB}$ in the high $\mathrm{PV}_{y}$ winter. We conclude that the large prior amplitude of the long-lived $\mathrm{UB}$ is due to a large prior SIC decline in BKS (Fig. 12b) because the large prior SIC decline can cause strong prior BKS warming and associated positive height anomaly in BKS. This can be seen from the time variation of the
BKS SAT anomaly shown in Fig. 12c (blue line). However, the prior BKS warming is less strong in the high $\mathrm{PV}_{y}$ winter (red line in Fig. 12c) on account of the prior SIC decline being weak (red line in Fig. 12b). We further see that there is a cold anomaly over Siberia or East Asia prior to the blocking onset in the low $\mathrm{PV}_{y}$ winter (Fig. 12d). Along with the establishment of UB the cold anomaly over Siberia or East Asia is further intensified to produce severe cold extremes, which is more intense and persistent for the long-lived UB than for the shortlived UB. While the long-lived UB leads to a smaller PV gradient within the blocking region (blue line in Fig. 12e), the long-lived UB requires the prior PV gradient being smaller than that of the short-lived UB.

The above results suggest that the small prior PV gradient over Eurasia is related not only to prior BKS warming (and SIC decline), but also to a weak prior cold 
anomaly in the East Asia. A small prior PV gradient is also seen as a prior cold anomaly emerges over Eurasian midlatitudes because the magnitude of the meridional $\mathrm{PV}$ gradient is mainly determined by the difference of the PV between high-latitude Arctic and midlatitude continent. When the PV gradient is smaller, a more intense and long-lived UB is easily formed once a largescale anticyclone appears in the small $\mathrm{PV}$ gradient region via the wave train propagation or eddy forcing (Luo et al. 2016b). This intense and long-lived UB can further reduce this PV gradient to generate a smaller PV gradient during the blocking episode. This allows us to infer such a causal linkage: A small prior PV gradient over Eurasia $\rightarrow$ a long-lived UB due to weakened energy dispersion and intensified nonlinearity $\rightarrow$ a smaller PV gradient within the blocking region during the blocking episode. In this causal chain, the small prior PV gradient is a favorable background condition for long-lived UB. Of course, the small PV gradient can also be generated by the internal variability, a problem we investigate in another paper. On the other hand, because a long-lived UB in winter can generally correspond to a small DJF-mean $\mathrm{PV}_{y}$, the magnitude of the winter-mean PV gradient is also considered as an indicator as defined above, which is crucial for the lifetime of UB and associated cold extremes.

While some of cold extremes do not necessarily require a large negative SIC anomaly in BKS, the above result suggests that a large negative BKS SIC anomaly indeed favors the generation of cold extremes in East Asia. To design the model experiment presented below, here we investigate whether the large negative SIC anomaly in BKS corresponds to a weakened PV gradient over Eurasia in the absence of UB events. It is found that the linear reduction trend of the DJF-mean $\mathrm{PV}_{y}$ anomaly corresponds to a downward (upward) trend of the BKS SIC (warming) (Fig. S2 in the online supplemental material). In the following numerical experiments, we prescribe a negative SIC anomaly or a warming anomaly in BKS to examine whether the BKS SIC decline or warming leads to the reduction of the PV gradient and the increase of the UB duration.

\section{Results of numerical experiments}

While the above analyses allow us to speculate on the causal links between $\mathrm{PV}_{y}$, SIC decline, and UB, it is useful to use model experiments to fully establish such a causal linkage. We conducted targeted numerical model experiments where we prescribe a negative SIC anomaly or a warming anomaly in the BKS region. We used the comprehensive SC-WACCM4 and the idealized GFDL dry dynamical core model to perform CTRL and BKS runs respectively. For SC-WACCM4 and dynamical core CTRL runs, the modeled DJF-mean blocking frequency distributions are shown in Fig. S3 of the online supplemental material. It is found that the two models are able to capture the NH climatological blocking frequency distribution, although the modeled blocking frequencies are somewhat lower than those revealed in the reanalysis data (Fig. 1b). In the GFDL CTRL run, the blocking frequency over the Ural Mountains is somewhat lower than that over Europe (Fig. S3b) and is somewhat different from that shown in Fig. 1b. Overall, the general consistency between the two model results reveals that the UB occurs even in the absence of moisture feedback or other complex physical parameterizations. However, we find that the WACCM4 model with complex physics processes including moistures (Fig. S3a) is more consistent with the reanalysis result (Fig. 1b) than the GFDL dry model.

In the SC-WACCM4 results, the difference between the BKS and CTRL runs isolates the role of the BKS SIC decline (shown in Fig. 13a) and shows a warming in $\mathrm{BKS}$, an induced cooling over Siberia, and an $\mathrm{AO}^{-}$-like pattern with an intensified Ural ridge and East Asian trough (Fig. 13c). This simulated anomalous $\mathrm{AO}^{-}$pattern is similar to our ERA-Interim reanalysis result (Fig. 2c), while the negative height anomaly is located farther east and Eurasian westerly wind anomalies are somewhat stronger. An increase of the blocking frequency is seen over the Ural Mountains and its adjacent region (Fig. 13d). It is found that $\mathrm{PV}_{y}$ in the Eurasian mid- to high latitudes prior to the blocking onset (a period from lag -30 to -20 days) is weakened (Fig. 13b) due to prior BKS warming related to prior SIC decline (Fig. 13a). We also show the time-longitude evolution of daily Z500 anomalies averaged over $50^{\circ}-70^{\circ} \mathrm{N}$ for blocking events of the SC-WACCM4 model in Figs. 13e and 13f for the CTRL and BKS run experiments, respectively. The comparison between the CTRL and BKS experiments shows that the duration of UB becomes longer (Fig. 13f) as a result of SIC decline. Thus, a significant increase in UB frequency in the mid- to high latitudes from $30^{\circ}$ to $120^{\circ} \mathrm{E}$ (Fig. 13d) is due to the presence of long-lasting high-latitude UB events (Fig. 13f).

We further explore the results in response to imposed BKS warming using the GFDL spectral dry dynamical core model as in Zhang et al. (2018b). The imposed heating in BKS is shown and described in Fig. S4 of the online supplemental material. In this paper, a perturbation experiment with a heating that has a maximum of $20 \mathrm{~K}$ in November is presented. It is found that there is a significant increase in the high-latitude blocking frequency over Eurasia around the Ural Mountains (Fig. 14a). The increased UB frequency is related to the reduction of the PV gradient due to BKS warming because the 
a

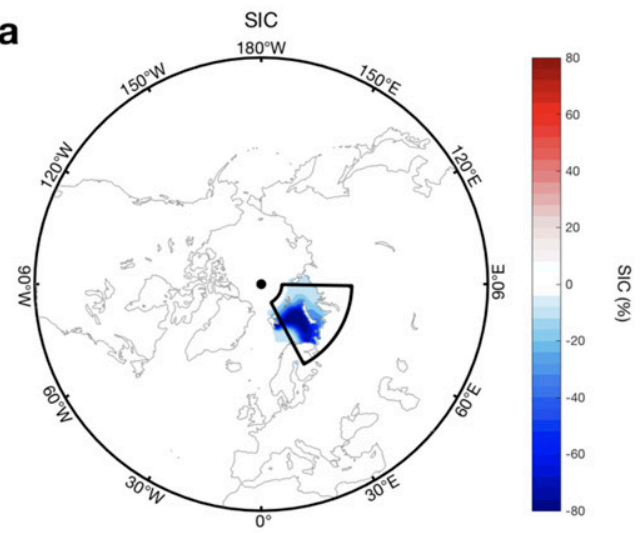

C

T850 \& Streamfunction

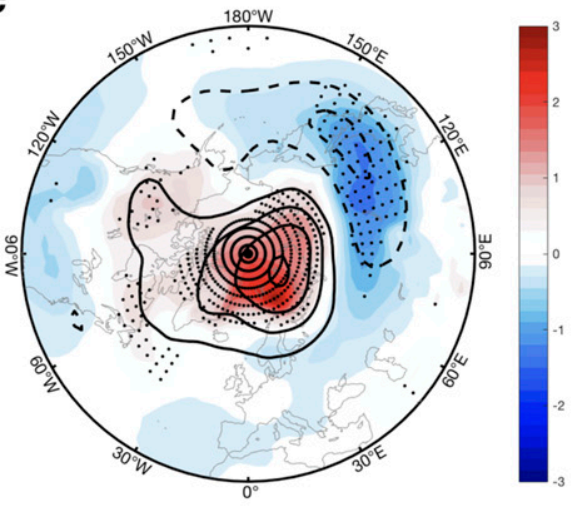

e

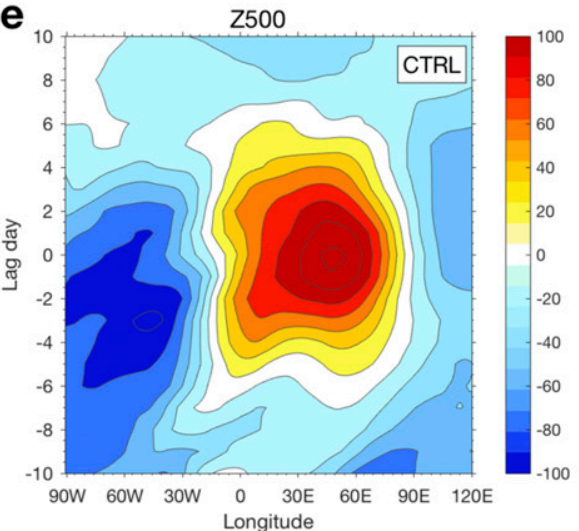

b

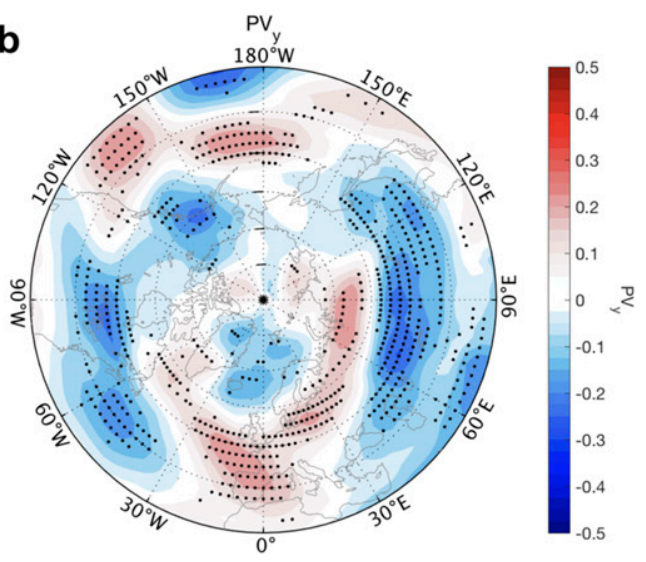

d

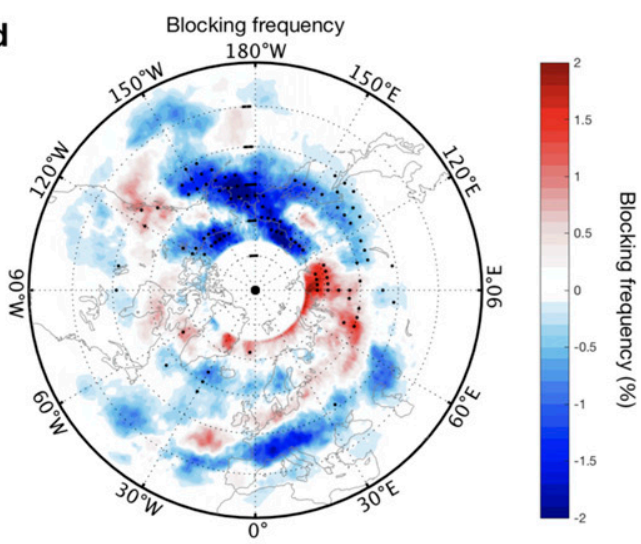

$\mathbf{f}$

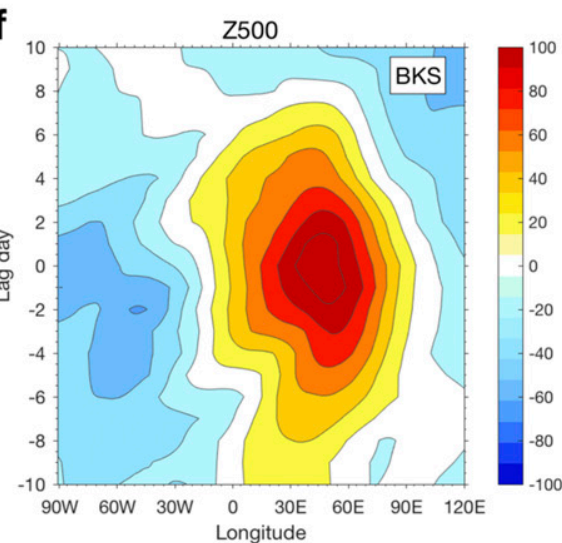

FIG. 13. The BKS-minus-CTRL-SIC differences of (a) prescribed SIC anomaly in winter, (b) time-mean nondimensional 500-hPa $\mathrm{PV}_{y}$ anomalies averaged over a time from lag -30 to -20 days prior to the blocking peak ( $\operatorname{lag} 0$ ), (c) 500-hPa streamfunction $\left(\mathrm{CI}=10^{6} \mathrm{~m}^{2} \mathrm{~s}^{-1}\right)$ and $850-\mathrm{hPa}$ air temperature (T850) anomalies, and (d) model blocking frequency (\%) for the SC-WACCM4 experiment results. Also shown are time-longitude evolution of Z500 anomalies (gpm) averaged over $50^{\circ}-70^{\circ} \mathrm{N}$ for the model UB events based on the $1 \mathrm{D}$ blocking index for (e) CTRL-run and (f) BKS-run experiments. The BKS run is performed with a low SIC prescribed in the BKS region [as depicted by the black-outlined area in (a)]. The stippling is as in Fig. 7.

BKS-minus-CTRL PV gradient difference prior to the blocking onset shows a negative anomaly over Eurasia near the Ural Mountains (Fig. 14b). We further found that the duration of UB is longer for the case with BKS warming than that without BKS warming (not shown), consistent with the result of the SC-WACCM model (Fig. 13d). Namely, the long lifetime of UB is related to SIC decline or warming in BKS. This increase in the blocking frequency is at variance with the results found in Hassanzadeh et al., who found a decrease in the 

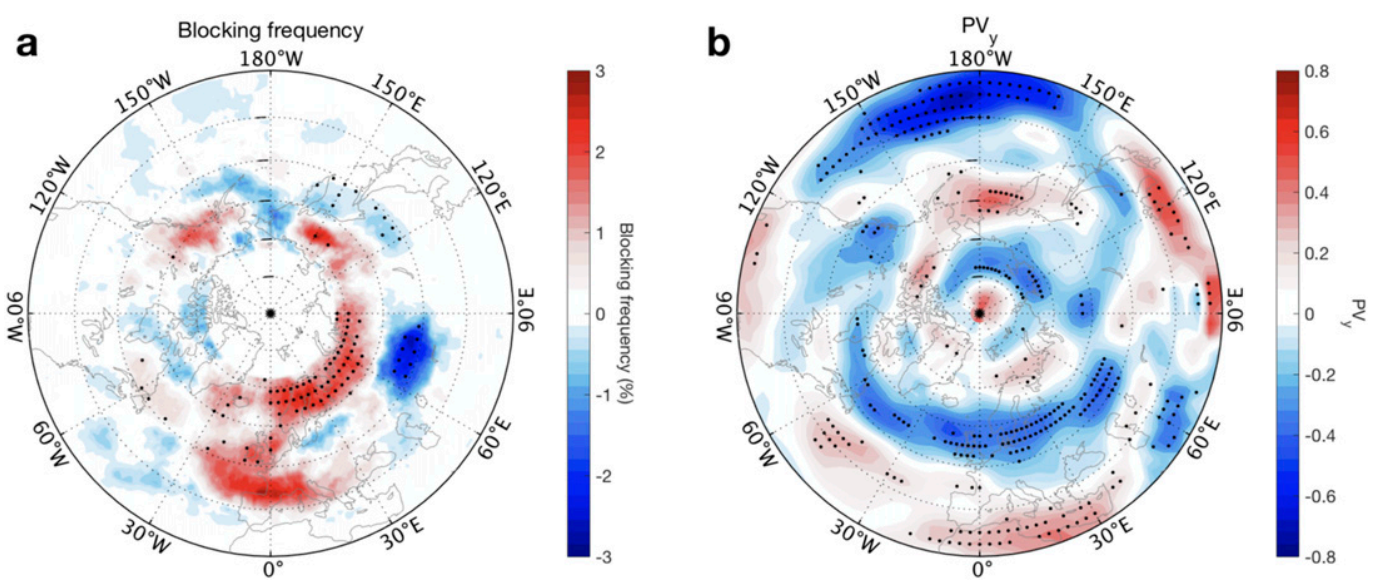

FIG. 14. Horizontal distributions of DJF-mean BKS-minus-CTRL differences of (a) blocking frequency and (b) timemean nondimensional 500-hPa $\mathrm{PV}_{y}$ anomalies averaged over a time from lag -30 to -20 days prior to the blocking peak (lag 0) for the model blocking events over the Ural region for the 20-K heating experiment of the GFDL spectral dry dynamical core model as described in the online supplemental material (Fig. S4). The stippling is as in Fig. 7.

blocking frequency as a result of decrease in equatorto-pole temperature gradient. Although the detailed mechanism warrants further analysis, the idealized model version used here better simulates the climatological winds and blocking than the zonally symmetric model version used in Hassanzadeh et al. (2014), which provides more confidence in the modeled change of blocking. While moist processes can affect the blocking (Ji and Tibaldi 1983; Pfahl et al. 2015), our model results here indicate that the BKS warming alone is able to increase the duration or persistence of UB event in the absence of moisture feedback and such an effect becomes more evident with more realistic representation of physics processes including moistures. The result that the BKS warming favors the increased duration of UB can also be explained by the theoretical result of Luo (2000), who found that the weak vertical shear of background westerly winds (reduced meridional temperature gradient) can weaken the energy dispersion of blocking to result in long-lived blocking. Thus, it is inferred that the increased UB frequency (Fig. 14b) is related to increased persistence of UB due to BKS warming or SIC decline.

\section{Conclusions and discussion}

Using both reanalysis data and atmospheric general circulation model experiments, we have established that a declining $\mathrm{PV}_{y}$ trend related to BKS warming and SIC loss is important for the increasing trend of cold extremes in East Asia in recent decades (Outten and Esau 2012; Cohen et al. 2014; Mori et al. 2014; Kug et al. 2015). This represents a new mechanism for linking midlatitude cold extremes to Arctic amplification and sea ice loss. Previous studies found that a weakening of zonal winds in strength, attributed to Arctic warming, is important for winter midlatitude cold extremes (Newson 1973; Petoukhov and Semenov 2010; Francis and Vavrus 2012; Walsh 2014; Luo et al. 2016a; Yao et al. 2017). Our investigation revealed that both the negative $\mathrm{AO}$ with a relatively large positive anomaly over the Ural region and a wave train with UB and NAO + contribute to the warm Arctic-cold Eurasia trend pattern and midlatitude Eurasian cold extreme trend, especially during 1990-2013, although they are influenced by the BKS SIC decline. Here, we further found that whether the recent Arctic SIC decline significantly affects midlatitude cold extremes depends strongly on the magnitude of the background PV gradient. Our result highlights the pivotal role of $\mathrm{PV}_{y}$ reduction to midlatitude cold extremes, and how this reduction can be reinforced by SIC decline. The declining trend of recent winter SIC in BKS may lead to increased high-latitude Ural blocking frequency and then increased cold extremes in midlatitude Eurasia through weakening the $\mathrm{PV}$ barrier. In this linkage, the weakened $\mathrm{PV}_{y}$ plays a central role for extending the UB lifetime when UB occurs. However, $\mathrm{PV}_{y}$ cannot directly influence midlatitude cold extremes when UB is absent. Thus, whether the magnitude of $\mathrm{PV}_{y}$ can significantly affect midlatitude cold extremes depends on whether the blocking occurs. It is further noted that while a small $\mathrm{PV}_{y}$ condition can be established by a large negative SIC anomaly or Arctic warming, it can also be generated by midlatitude cold anomalies over Eurasia even in the absence of large negative BKS SIC anomalies. The combination of Arctic warming and midlatitude cooling backgrounds can lead to a smaller background $\mathrm{PV}_{y}$ over Eurasia before midlatitude cold extremes take place. 


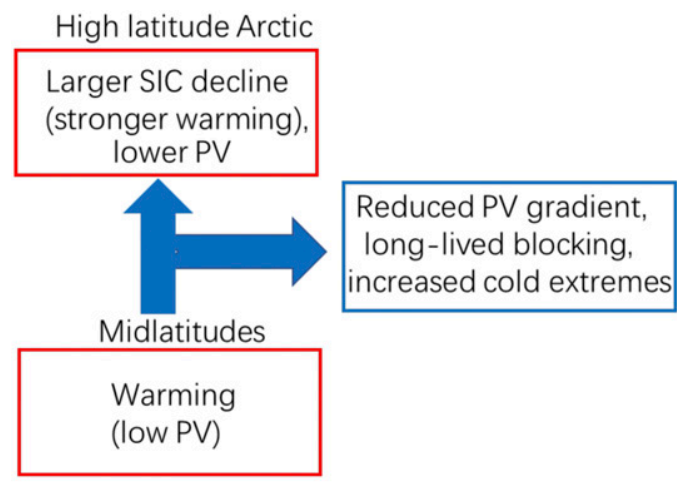

(a)

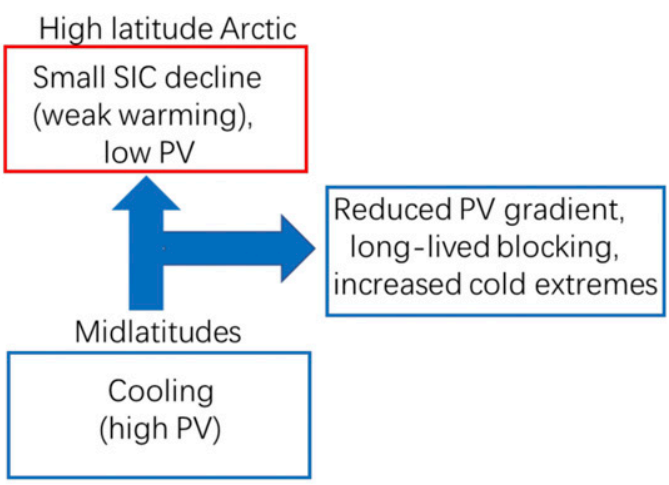

(b)

FIG. 15. A schematic diagram of the conditions of meridional PV gradient reduction or weakened PV barrier leading to increased cold extremes: (a) Arctic warming (SIC decline) must be stronger (larger) in the BKS when there is a warming background over the midlatitude continent, and (b) Arctic warming may be weak when there is a cooling background over the midlatitude continent.

Our study reveals the conditions when the cold extremes over Eurasia depend on the BKS SIC decline and when these cold extremes are independent of the BKS SIC decline. The frequency of cold extremes over midlatitude Eurasia is more sensitive to the magnitude of the meridional PV gradient anomaly than to the magnitude of the SIC anomaly in BKS. In fact, the magnitude of the meridional PV gradient is mainly determined by the relative values of the PV in midlatitude continents and high-latitude Arctic. Because the warm anomaly corresponds to a reduced PV and the cold anomaly corresponds to an enhanced PV, the magnitude of $\mathrm{PV}_{y}$ depends not only on the BKS SIC or SAT anomaly in the high-latitude Arctic, but also on whether there is a midlatitude warming or cooling, as described in Fig. 15. The negative BKS SIC anomaly must be large and the BKS temperature anomalies must be high so that the meridional PV gradient is small (Fig. 15a) when the midlatitude Eurasian continent is warm. Under such small $\mathrm{PV}_{y}$ conditions, increased persistence of UB is observed, which leads to increased midlatitude cold extremes. In contrast, $\mathrm{PV}_{y}$ may be small when the Eurasian midlatitude continent is cold, even though the negative BKS SIC anomaly or BKS warming is weak (Fig. 15b). In this case, long-lived UB and increased cold extremes are still seen in the Eurasian continent. Thus, midlatitude cold extremes over Eurasia do not require a large negative SIC anomaly in BKS if the midlatitude Eurasian continent itself is cold. This means that a small $\mathrm{PV}_{y}$ in Eurasian mid-high latitudes, rather than BKS SIC decline or warming, is a necessary condition for intense midlatitude cold extremes.

While the BKS SIC trend mainly determines the positive trend of East Asia cold extremes through reduced PV gradient trend in the recent decades (since 1979), cold extremes on interannual time scales are not only related to the winter SIC decline, but also related to cold midlatitude Eurasia probably due to internal atmospheric variability. This allows us to establish a causal linkage pathway: SIC loss/warming in BKS or cold midlatitude Eurasia $\rightarrow$ reduced PV gradient $\rightarrow$ longlived UB $\rightarrow$ strong Eurasian cold extremes. For a shorttime trend there is a preferred pathway of "SIC loss/ warming in BKS $\rightarrow$ reduced PV gradient $\rightarrow$ long-lived UB $\rightarrow$ strong Eurasian cold extremes" in the recent decades during 1979-2013, but another preferred pathway of "cold midlatitude Eurasia $\rightarrow$ reduced PV gradient $\rightarrow$ long-lived UB $\rightarrow$ strong cold extremes over Eurasia" during a nondeclining SIC period (e.g., 1955-75). During 1955-75 a small PV gradient can be generated by the cold midlatitude Eurasia and frequently winter Eurasian cold extremes are still observed. The cold midlatitude Eurasia as a decadal background is more likely related to decadal or interdecadal atmospheric variability modulated by oceanic processes (Dai et al. 2015). The investigation of this issue will be reported in another paper. We must bear in mind that the magnitude of background PV gradient is a key controller of Arctic-midlatitude weather linkages. Whether the BKS SIC decline/ warming in the recent decades affects midlatitude weather patterns depends mainly on the magnitude of background PV gradient and if blocking is present. Another important problem we should examine is to evaluate the different contributions of the recent BKS warming/SIC decline and internal variability to the background PV gradient change. This problem is beyond the scope of the present paper, which deserves a further investigation. 
Midlatitude cold extremes are weak even in the presence of large SIC decline when the PV gradient is not small. Thus, this would explain why some model experiments with SIC reductions have large responses while others do not. We hypothesize that the PV barrier theory of the Arctic-midlatitude linkage proposed here may be valid in other Arctic regions and seasons.

Acknowledgments. Luo and Chen acknowledge the support from the National Key Research and Development Program of China (2016YFA0601802), the National Natural Science Foundation of China (Grants 41430533 and 41790473) and the Chinese Academy of Science Strategic Priority Research Program (Grant XDA 19070403). Overland was supported by the Arctic Research Program of the NOAA Climate Prediction Office (PMEL Contribution 4765). Simmonds was supported by the Australian Research Council (DP16010997). Authors YW and PZ are supported by the U.S. National Science Foundation under AGS-1815128. The authors thank Prof. Aiguo Dai for his constructive suggestions on an early draft of the paper.

\section{REFERENCES}

Berggren, R., B. Bolin, and C.-G. Rossby, 1949: An aerological study of zonal motion, its perturbations and break-down. Tellus, 1, 14-37, https://doi.org/10.3402/tellusa.v1i2.8501.

Chen, L., J. Francis, and E. Hanna, 2018: The "warm-Arctic/coldcontinents" pattern during 1901-2010. Int. J. Climatol., 38, 5245-5254, https://doi.org/10.1002/joc.5725.

Chen, X., D. Luo, S. Feldstein, and S. Lee, 2018: Impact of winter Ural blocking on Arctic sea ice: Short-time variability. J. Climate, 31, 2267-2282, https://doi.org/10.1175/JCLI-D-17-0194.1.

Cheung, H. N., W. Zhou, Y. Shao, W. Chen, H. Y. Mok, and M. C. $\mathrm{Wu}, 2013$ : Observational climatology and characteristics of wintertime atmospheric blocking over Ural-Siberia. Climate Dyn., 41, 63-79, https://doi.org/10.1007/s00382-012-1587-6.

Cohen, J., and Coauthors, 2014: Recent Arctic amplification and extreme mid-latitude weather. Nat. Geosci., 7, 627-637, https://doi.org/10.1038/ngeo2234.

_- and Coauthors, 2018: Arctic change and possible influence on mid-latitude climate and weather. U.S. CLIVAR Rep. 2018-1, 41 pp., https://doi.org/10.5065/D6TH8KGW.

Comiso, J. C., 2006: Abrupt decline in the Arctic winter sea ice cover. Geophys. Res. Lett., 33, L18504, https://doi.org/10.1029/ 2006GL027341.

Dai, A., J. C. Fyfe, S.-P. Xie, and X. Dai, 2015: Decadal modulation of global-mean temperature by internal climate variability. Nat. Climate Change, 5, 555-559, https://doi.org/10.1038/ nclimate2605.

Davini, P., C. Cagnazzo, S. Gualdi, and A. Navarra, 2012: Bidimensional diagnostics, variability, and trends of Northern Hemisphere blocking. J. Climate, 25, 6496-6509, https:// doi.org/10.1175/JCLI-D-12-00032.1.

Dee, D. P., and Coauthors, 2011: The ERA-Interim reanalysis: Configuration and performance of the data assimilation sys- tem. Quart. J. Roy. Meteor. Soc., 137, 553-597, https://doi.org/ 10.1002/qj.828.

Diao, Y., J. Li, and D. Luo, 2006: A new blocking index and its application: Blocking action in the Northern Hemisphere. J. Climate, 19, 4819-4839, https://doi.org/10.1175/JCLI3886.1.

Francis, J. A., and S. J. Vavrus, 2012: Evidence linking Arctic amplification to extreme weather in mid-latitudes. Geophys. Res. Lett., 39, L06801, https://doi.org/10.1029/2012GL051000.

Gillett, N. P., and Coauthors, 2008: Attribution of polar warming to human influence. Nat. Geosci., 1, 750-754, https://doi.org/ 10.1038/ngeo338.

Gu, S., Y. Zhang, Q. Wu, and X. Yang, 2018: The linkage between Arctic sea ice and midlatitude weather: In the perspective of energy. J. Geophys. Res. Atmos., 123, 11 536-11 550, https:// doi.org/10.1029/2018JD028743.

Hassanzadeh, P., Z. Kuang, and B. F. Farrell, 2014: Responses of midlatitude blocks and wave amplitude to changes in the meridional temperature gradient in an idealized dry GCM. Geophys. Res. Lett., 41, 5223-5232, https://doi.org/10.1002/ 2014 GL060764.

Hoskins, B. J., M. E. McIntyre, and A. W. Robertson, 1985: On the use and significance of isentropic potential vorticity maps. Quart. J. Roy. Meteor. Soc., 111, 877-946, https://doi.org/ 10.1002/qj.49711147002.

Hurrell, J. W., and Coauthors, 2013: The Community Earth System Model: A framework for collaborative research. Bull. Amer. Meteor. Soc., 94, 1339-1360, https://doi.org/10.1175/BAMS-D12-00121.1.

Iwasaki, T., T. Shoji, Y. Kanno, M. Sawada, M. Ujiie, and K. Takaya, 2014: Isentropic analysis of polar cold airmass streams in the Northern Hemispheric winter. J. Atmos. Sci., 71, 2230-2243, https://doi.org/10.1175/JAS-D-13-058.1.

Ji, L., and S. Tibaldi, 1983: Numerical simulation of a case of blocking: The effects of orography and land-sea contrast. Mon. Wea. Rev., 111, 2068-2086, https://doi.org/10.1175/15200493(1983)111<2068:NSOACO > 2.0.CO;2.

Kelleher, M., and J. Screen, 2018: Atmospheric precursors of and response to anomalous Arctic sea ice in CMIP5 models. $A d v$. Atmos. Sci., 35, 27-37, https://doi.org/10.1007/s00376-017-7039-9.

Kug, J.-S., and Coauthors, 2015: Two distinct influences of Arctic warming on cold winters over North America and East Asia. Nat. Geosci., 8, 759-762, https://doi.org/10.1038/ngeo2517.

Li, S. L., 2004: Influence of the northwest Atlantic SST anomaly on the circulation over the Ural Mountains. J. Meteor. Soc. Japan, 82, 971-988, https://doi.org/10.2151/jmsj.2004.971.

Luo, B., D. Luo, L. Wu, L. Zhong, and I. Simmonds, 2017: Atmospheric circulation patterns which promote winter Arctic sea ice decline. Environ. Res. Lett., 12, 054017, https://doi.org/ 10.1088/1748-9326/aa69d0.

Luo, D., 2000: Planetary-scale baroclinic envelope Rossby solitons in a two-layer model and their interaction with synoptic-scale eddies. Dyn. Atmos. Oceans, 32, 27-74, https://doi.org/ 10.1016/S0377-0265(99)00018-4

, 2005: A barotropic envelope Rossby soliton model for blockeddy interaction. Part I: Effect of topography. J. Atmos. Sci., 62, 5-21, https://doi.org/10.1175/1186.1.

, and J. Li, 2000: Barotropic interaction between planetary and synoptic-scale waves during the life cycles of blockings. $A d v$. Atmos. Sci., 17, 649-670, https://doi.org/10.1007/s00376-0000026-5.

- J. Cha, L. Zhong, and A. Dai, 2014: A nonlinear multiscale interaction model for atmospheric blocking: The eddy-blocking 
matching mechanism. Quart. J. Roy. Meteor. Soc., 140, 17851808, https://doi.org/10.1002/qj.2337.

— , Y. Yao, and A. Dai, 2015a: Decadal relation between European blocking and North Atlantic Oscillation during 19782011. Part I: Atlantic conditions. J. Atmos. Sci., 72, 1152-1173, https://doi.org/10.1175/JAS-D-14-0039.1.

,$- \ldots$, and -2015 b: Decadal relation between European blocking and North Atlantic Oscillation during 1978-2011. Part II: A theoretical model study. J. Atmos. Sci., 72, 11741199, https://doi.org/10.1175/JAS-D-14-0040.1.

, Y. Xiao, Y. Yao, A. Dai, I. Simmonds, and C. L. E. Franzke, 2016a: Impact of Ural blocking on winter warm Arctic-cold Eurasian anomalies. Part I: Blocking-induced amplification. J. Climate, 29, 3925-3947, https://doi.org/10.1175/JCLI-D-15-0611.1.

, - _ Y. Diao, A. Dai, C. L. E. Franzke, and I. Simmonds, 2016b: Impact of Ural Blocking on winter warm Arctic-cold Eurasian anomalies. Part II: The link to the North Atlantic Oscillation. J. Climate, 29, 3949-3971, https://doi.org/10.1175/ JCLI-D-15-0612.1.

— X. Chen, A. Dai, and I. Simmonds, 2018a: Changes in atmospheric blocking circulations linked with winter Arctic warming: A new perspective. J. Climate, 31, 7661-7678, https:// doi.org/10.1175/JCLI-D-18-0040.1.

,-- , and S. Feldstein, 2018b: Linear and nonlinear dynamics of North Atlantic Oscillations: A new thinking of symmetry breaking. J. Atmos. Sci., 75, 1955-1977, https://doi.org/10.1175/ JAS-D-17-0274.1.

Marsh, D. R., M. J. Mills, D. E. Kinnison, J. Lamarque, N. Calvo, and L. M. Polvani, 2013: Climate change from 1850 to 2005 simulated in CESM1(WACCM). J. Climate, 26, 7372-7391, https://doi.org/10.1175/JCLI-D-12-00558.1.

McCusker, K. E., J. C. Fyfe, and M. Sigmond, 2016: Twenty-five winters of unexpected Eurasian cooling unlikely due to Arctic sea-ice loss. Nat. Geosci., 9, 838-842, https://doi.org/10.1038/ ngeo2820.

Meleshko, V. P., V. M. Kattsov, V. M. Mirvis, A. V. Baidin, T. V. Pavlova, and V. A. Govorkova, 2018: Is there a link between Arctic sea ice loss and increasing frequency of extremely cold winters in Eurasia and North America? Synthesis of current research. Russ. Meteor. Hydrol., 43, 743-755, https://doi.org/ 10.3103/S1068373918110055.

Mori, M., M. Watanabe, H. Shiogama, J. Inoue, and M. Kimoto, 2014: Robust Arctic sea-ice influence on the frequent Eurasian cold winters in past decades. Nat. Geosci., 7, 869-873, https:// doi.org/10.1038/ngeo2277.

Newson, R. L., 1973: Response of general circulation model of the atmosphere to removal of the Arctic ice-cap. Nature, 241, 3940, https://doi.org/10.1038/241039b0.

Outten, S., and I. Esau, 2012: A link between Arctic sea ice and recent cooling trends over Eurasia. Climatic Change, 110, 1069-1075, https://doi.org/10.1007/s10584-011-0334-z.

Overland, J. E., and M. Wang, 2018: Arctic-midlatitude weather linkages in North America. Polar Sci., 16, 1-9, https://doi.org/ 10.1016/j.polar.2018.02.001.

_ J. A. Francis, R. Hall, E. Hanna, S. Kim, and T. Vihma, 2015: The melting Arctic and mid-latitude weather patterns: Are they connected? J. Climate, 28, 7917-7932, https://doi.org/ 10.1175/JCLI-D-14-00822.1.

— weather to the changing Arctic. Nat. Climate Change, 6, 992 998, https://doi.org/10.1038/nclimate3121.

Petoukhov, V., and V. A. Semenov, 2010: A link between reduced Barents-Kara sea ice and cold winter extremes over northern continents. J. Geophys. Res., 115, D21111, https://doi.org/ 10.1029/2009JD013568.

Pfahl, S., C. Schwierz, M. Croci-Maspoli, C. M. Grams, and H. Wernli, 2015: Importance of latent heat release in ascending air streams for atmospheric blocking. Nat. Geosci., 8 , 610-615, https://doi.org/10.1038/ngeo2487.

Rex, D. F., 1950: Blocking action in the middle troposphere and its effect upon regional climate. I. An aerological study of blocking action. Tellus, 2, 196-211, https://doi.org/10.3402/ tellusa.v2i3.8546.

Sato, K., J. Inoue, and M. Watanabe, 2014: Influence of the Gulf Stream on the Barents Sea ice retreat and Eurasian coldness during early winter. Environ. Res. Lett., 9, 084009, https:// doi.org/10.1088/1748-9326/9/8/084009.

Screen, J. A., and I. Simmonds, 2010: The central role of diminishing sea ice in recent Arctic temperature amplification. Nature, 464, 1334-1337, https://doi.org/10.1038/nature09051.

_ , T. J. Bracegirdle, and I. Simmonds, 2018: Polar climate change as manifest in atmospheric circulation. Curr. Climate Change Rep., 4, 383-395, https://doi.org/10.1007/s40641-0180111-4.

Shepherd, T. G., 2016: Effect of a warming Arctic. Science, 353, 989-990, https://doi.org/10.1126/science.aag2349.

Shoji, T., Y. Kanno, and T. Iwasaki, 2014: An isentropic analysis of the temporal evolution of East Asian cold air outbreaks. J. Climate, 27, 9337-9348, https://doi.org/10.1175/JCLI-D-14-00307.1.

Simmonds, I., 2015: Comparing and contrasting the behaviour of Arctic and Antarctic sea ice over the 35 year period 1979-2013. Ann. Glaciol., 56, 18-28, https://doi.org/10.3189/2015AoG69a909. , 2018: What causes extreme hot days in Europe? Environ. Res. Lett., 13, 071001, https://doi.org/10.1088/1748-9326/aacc78.

_- and P. D. Govekar, 2014: What are the physical links between Arctic sea ice loss and Eurasian winter climate? Environ. Res. Lett., 9, 101003, https://doi.org/10.1088/17489326/9/10/101003.

Smith, K. L., R. R. Neely, D. R. Marsh, and L. M. Polvani, 2014: The Specified Chemistry Whole Atmosphere Community Climate Model (SC-WACCM). J. Adv. Model. Earth Syst., 6, 883-901, https://doi.org/10.1002/2014MS000346.

Steele, M., W. Ermold, and J. Zhang, 2008: Arctic Ocean surface warming trends over the past 100 years. Geophys. Res. Lett. 35, L02614, https://doi.org/10.1029/2007GL031651.

Stroeve, J. C., and Coauthors, 2011: Sea ice response to an extreme negative phase of the Arctic Oscillation during winter 2009/ 2010. Geophys. Res. Lett., 38, L02502, https://doi.org/10.1029/ 2010GL045662.

Sun, L., J. Perlwitz, and M. Hoerling, 2016: What caused the recent "warm Arctic, cold continents" trend pattern in winter temperatures? Geophys. Res. Lett., 43, 5345-5352, https://doi.org/ 10.1002/2016GL069024.

Sung, M.-K., S.-H. Kim, B.-M. Kim, and Y.-S. Choi, 2018: Interdecadal variability of the warm Arctic and cold Eurasia pattern and its North Atlantic origin. J. Climate, 31, 5793-5810, https://doi.org/10.1175/JCLI-D-17-0562.1.

Tibaldi, S., and F. Molteni, 1990: On the operational predictability of blocking. Tellus, 42A, 343-365, https://doi.org/10.3402/ tellusa.v42i3.11882.

Vihma, T., 2014: Effects of Arctic sea ice decline on weather and climate: A review. Surv. Geophys., 35, 1175-1214, https:// doi.org/10.1007/s10712-014-9284-0.

Walsh, J. E., 2014: Intensified warming of the Arctic: Causes and impacts on middle latitudes. Global Planet. Change, 117, 5263, https://doi.org/10.1016/j.gloplacha.2014.03.003. 
Wilks, D. S., 2011: Statistical Methods in the Atmospheric Sciences, 2nd ed. Elsevier, 627 pp.

Woods, C., and R. Caballero, 2016: The role of moist intrusions in winter Arctic warming and sea ice decline. J. Climate, 29, 4473-4485, https://doi.org/10.1175/JCLI-D-15-0773.1.

Wu, Z., and T. Reichler, 2018: Towards a more Earth-like circulation in idealized models. J. Adv. Model. Earth Syst., 10, 1458-1469, https://doi.org/10.1029/2018ms001356.

Yang, Z., W. Huang, B. Wang, R. Chen, J. S. Wright, and W. Ma, 2018: Possible mechanisms for four regimes associated with cold events over East Asia. Climate Dyn., 51, 35-56, https:// doi.org/10.1007/s00382-017-3905-5.

Yao, Y., D. Luo, A. Dai, and I. Simmonds, 2017: Increased quasistationarity and persistence of Ural blocking and Eurasian extreme cold events in response to Arctic warming. Part I: Insight from observational Analyses. J. Climate, 30, 35493568, https://doi.org/10.1175/JCLI-D-16-0261.1.

Ye, K., T. Jung, and T. Semmler, 2018: The influences of the Arctic troposphere on the midlatitude climate variability and the recent Eurasian cooling. J. Geophys. Res. Atmos., 123, $10162-$ 10184 , https://doi.org/10.1029/2018JD028980.
Yeh, T. C., 1949: On energy dispersion in the atmosphere. J. Meteor., 6, 1-16, https://doi.org/10.1175/1520-0469(1949)006<0001: OEDITA $>2.0 . \mathrm{CO} ; 2$.

Zhang, P., Y. Wu, I. Simpson, K. L. Smith, X. Zhang, B. De, and P. Callaghan, 2018a: A stratospheric pathway linking a colder Siberia to Barents-Kara sea ice loss. Sci. Adv., 4, eaat6025, https://doi.org/10.1126/sciadv.aat6025.

, -, and K. Smith, 2018b: Prolonged effect of the stratospheric pathway in linking Barents-Kara Sea sea ice variability to the midlatitude circulation in a simplified model. Climate Dyn., 50, 527-539, https://doi.org/10.1007/s00382-0173624-y.

Zhang, R., C. Sun, R. Zhang, L. Jia, and W. Li, 2018: The impact of Arctic sea ice on the inter-annual variations of summer Ural blocking. Int. J. Climatol., 38, 4632-4650, https://doi.org/ 10.1002/joc.5731.

Zhong, L., L. Hua, and D. Luo, 2018: Local and external moisture sources for the Arctic warming over the Barents-Kara Seas. J. Climate, 31, 1963-1982, https://doi.org/10.1175/JCLI-D-170203.1. 